\title{
On the role of $N$-methylmorpholine- $N$-oxide (NMMO) in the generation of elemental transition metal precipitates in cellulosic materials
}

\author{
Thomas Rosenau $\mathbb{D} \cdot$ Antje Potthast $(\mathbb{D} \cdot$ Hubert Hettegger $(\mathbb{D} \cdot$ Markus Bacher $\mathbb{D} \cdot$ \\ Martina Opietnik • Thomas Röder • Immanuel Adorjan
}

Received: 31 May 2021/ Accepted: 27 August 2021/Published online: 15 September 2021

(C) The Author(s) 2021

\begin{abstract}
Several literature reports describe the role of aqueous solutions of $\mathrm{N}$-methylmorpholine- $\mathrm{N}$-oxide monohydrate (NMMO) as a suitable medium for the generation of transition metal (nano)particles in or on cellulosic materials and further elaborate its role as a co-reactant of the transition metal salts that are reduced to the elemental metal. However, this would assign NMMO the role of a reductant, which is in contradiction of its obvious oxidative nature. In the present study, the exemplary cases of silver, gold, and platinum salts as the precursors of the respective metal (nano)particles in aqueous NMMO/cellulose mixtures were investigated. Naturally, NMMO did not act as a reducing agent in any case-this role was taken over by the frequently used NMMO stabilizer propyl
\end{abstract}

T. Rosenau ( $\varangle)$ · A. Potthast · H. Hettegger · M. Bacher Vienna (BOKU), Institute of Chemistry of Renewable Resources, University of Natural Resources and Life Sciences, Muthgasse 18, 1190 Vienna, Austria

e-mail: thomas.rosenau@boku.ac.at

T. Rosenau

Johan Gadolin Process Chemistry Centre, Åbo Akademi University, Porthansgatan 3, 20500 Åbo/Turku, Finland gallate, or by cellulose itself, into which carbonyl and carboxyl groups were introduced. Also, hypochlorite-produced intermediately from chloride ions and subsequently undergoing disproportionation into chloride and chlorate-or transient $N$-methylene(morpholinium) ions generated from NMMO, which are in turn oxidized to formyl morpholide, can act as the corresponding reductants while the metal ions are reduced, depending on the reaction conditions. Apart from providing interesting mechanistic insights, the study points to the importance of a precise description of the composition of the chemical systems used, as well as the importance of seemingly inert auxiliaries, which turned out to be essential co-reactants in the metal (nano)particle generation.

\author{
M. Opietnik · T. Röder \\ Lenzing AG, Werkstrasse 2, 4860 Lenzing, Austria \\ I. Adorjan \\ Alltek Vertriebs, GmbH \& Co KG, Wolfenberger Str. 2, \\ 3100 St. Pölten, Austria
}




\section{Graphic abstract}

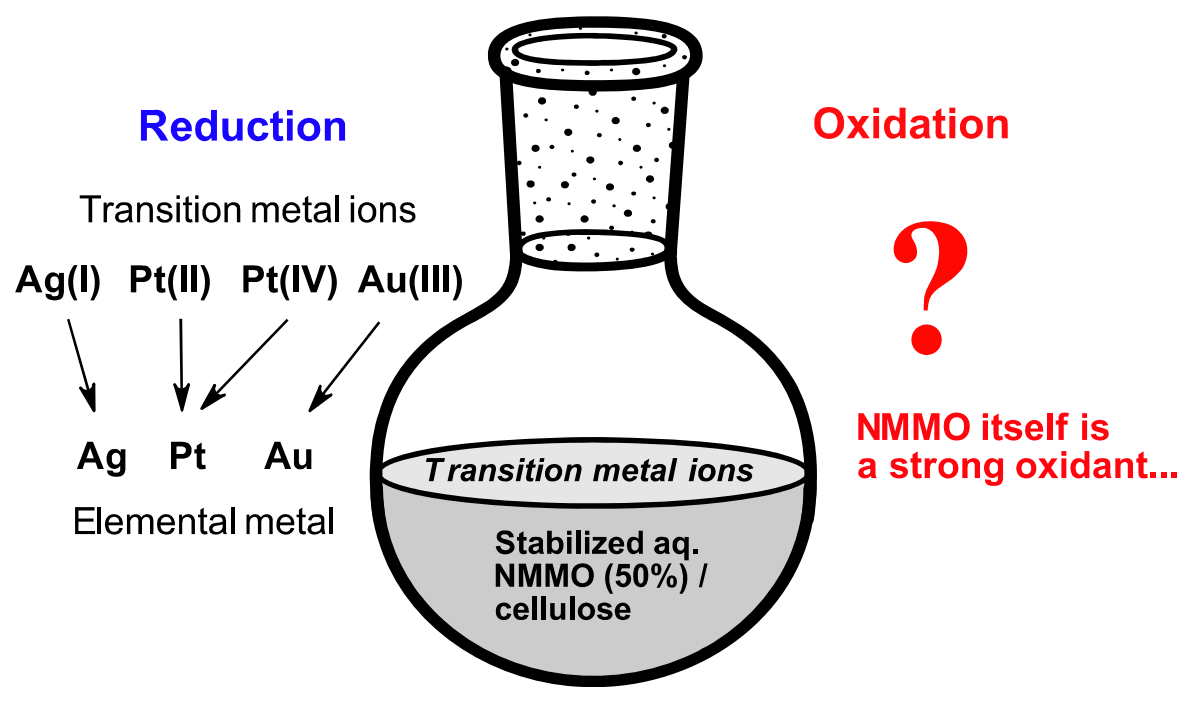

Keywords Cellulose - Lyocell · NMMO - Propyl gallate $\cdot$ Reaction mechanism $\cdot$ Redox reaction . Transition metal nanoparticles

\section{Introduction}

The use of $N$-methylmorpholine- $N$-oxide monohydrate (NMMO, 1) in the manufacture of cellulosic products according to the lyocell technology, mostly fibers, is well established on an industrial scale. While more dilute aqueous solutions of NMMO have a swelling effect on cellulosic pulp, the respective monohydrate is able to dissolve cellulose at elevated temperatures above $80{ }^{\circ} \mathrm{C}$ so that a spinnable dope is obtained. In theory, this dissolution process is merely physical, but in practice quite many side reactions might occur (Rosenau et al. 2001), which, however, can efficiently be suppressed by the addition of appropriate stabilizers. Propyl gallate (PG, gallic acid propyl ester, 2) is the most common one of them (Rosenau et al. 2002a,b), which is even applied on an industrial scale, but also a non-acidic process medium contributes to minimizing degradation reactions of the solvent. Potential hazards of improper handling of NMMO in its different application fields (cellulose dissolution and fiber/film manufacture, biomass pretreatment, organic synthesis) have recently be summarized and pointed out (Rosenau and French 2021).
The lyocell system has very frequently been used also on a laboratory scale for research on novel cellulosic products, especially the embedding of particles and nanoparticles into cellulosic matricesin most cases fibers, but also films, beads, and pulp (Firgo et al. 1995; Marini and Bruneis 1996; Fink et al. 2001; Sayyed et al. 2019). The incorporation into fibers can be achieved either by (nano)particlecontaining dopes, which are then spun out, or by swelling cellulosic substrates in aqueous NMMO and precipitating the nanoparticles into/onto this matrix (Shah et al. 2013). The by far most dominant topic in this regard is the generation of transition metal precipitates, in particular from silver, because of its antimicrobial/antibacterial properties (Smiechowicz et al. 2011, 2018, 2020,2019; Rac-Rumijowska et al. 2017). But also gold nanoparticles have been studied (Yokota et al. 2008; Kitaoka et al. 2011; Hatakeyama et al. 2019), as well as platinum and lanthanide equivalents (Erdman et al. 2016; Skwierczyńska et al. 2019). Luminescent cellulosic fibers have been obtained from an aqueous NMMO medium by incorporating europium-doped (Kulpinski et al. 2012) or terbium-doped (Kulpinski et al. 2016) particles into the matrix. In general, NMMO has been characterized as a co-reactant for the transition metal ions and swelling agent for cellulose, which provides a beneficial environment for both nanoparticle generation (instead of larger precipitates) and their incorporation into the cellulose matrix (instead of mere surface 
adsorption). While this medium has apparently proved to be quite reliable and thus has gained popularity for the generation of transition metal precipitates in cellulosic fibers, there is still a puzzling question about this system from a chemical point of view, which has not yet been pointed out so far.

The formation of transition metal particles from metal salts is evidently not just a physical/mechanical process that causes the transition from the macro- to the micro- or nano-scale-such as the formation of nano-fibrillated cellulose from cellulosic precursors. It is a true chemical reaction, more specifically a reduction of metal cations to elemental metals, i.e., from a positive oxidation state to oxidation state zero. Obviously, an isolated oxidation process does not exist-any oxidation is accompanied by a corresponding reduction, both reactions together constituting a redox pair. However, NMMO is a strong oxidant itself and certainly not capable of functioning as a direct reducing agent for the transition metal cations (Albini 1993; Pieterse 2013). This puts us in the somewhat paradoxical situation that a relatively commonly used reaction system exists that has been successfully applied to the synthesis of elaborate (nano)particle-containing cellulosic matrices, but its chemistry is apparently not at all well understood, and in some cases incorrectly portrayed in the literature. In short, NMMO's reported role as a coreactant and the nature of the reductant effecting generation of the transition metals from their salts remain unclear.

In this study, we have investigated the chemistry of different systems for the generation of transition metal precipitates on cellulosic substrates in aqueous NMMO in more detail, especially concerning the redox reactions taking place. When elemental metal species are formed by reduction, something else must, in turn, be oxidized. The identification of these redox processes was thus the major task.

\section{Materials and methods}

\section{General}

All chemicals were obtained from Sigma-Aldrich (Schnelldorf, Germany). Thin-layer chromatography (TLC) was performed on silica gel 60 plates
$(5 \times 10 \mathrm{~cm}, 0.25 \mathrm{~mm})$ with fluorescence detection under UV light at $254 \mathrm{~nm}$. Transition metal salts were of the highest purity commercially available. $N$ Methylmorpholine- $N$-oxide was recrystallized from dioxane, $\mathrm{N}$-methylmorpholine- $\mathrm{N}$-oxide monohydrate from acetone. Bidistilled water was used throughout. Propyl gallate was recrystallized from toluene until colorless and stored in the dark in a tightly closed vessel under Ar. The usual slightly yellow appearance of this compound points to trace impurities from ellagic acid and its bis(ortho-quinone). The silver ion concentration in aqueous solution was determined by means of an ion-selective electrode (ISE-3, Thomas Scientific, Swedesboro, New Jersey, USA) after adjustment to $\mathrm{pH} 6$ with $0.1 \mathrm{M}$ aqueous $\mathrm{HNO}_{3}$. By the addition of different NMMO and $\mathrm{N}$-methylmorpholine (NMM) concentrations to a blank of $1 \mathrm{mM}$ $\mathrm{AgNO}_{3}$ solution, it was confirmed that the presence of the organic compounds did not influence the result of the measurement.

NMR experiments were carried out on a Bruker Avance II 400 instrument $\left({ }^{1} \mathrm{H}\right.$ resonance at $400.13 \mathrm{MHz},{ }^{13} \mathrm{C}$ resonance at $100.62 \mathrm{MHz}$ ), equipped with a $5 \mathrm{~mm}$ broadband probe head (BBFO) with z-gradient. Standard Bruker pulse programs were used. Data collection: $32 \mathrm{k}$ data points, apodization with a Gaussian window function $(\mathrm{GB}=0.3)$ prior to Fourier transformation. Acquisition time: $2.5 \mathrm{~s}$, relaxation delay: $1 \mathrm{~s}$. Bruker TopSpin 3.5 software was used for the acquisition and processing of the NMR data. Spectra were recorded in $\mathrm{CDCl}_{3}$ in the case of isolated compounds (e.g. tocopherol derivative, $\mathrm{N}$ formylmorpholine) or $\mathrm{D}_{2} \mathrm{O}$ (direct measurement of NMMO reaction mixtures). Chemical shifts are given in $\delta \mathrm{ppm}$ values relative to TMS as the internal standard, coupling constants are given in $\mathrm{Hz} .{ }^{13} \mathrm{C}$ peak assignment was done through APT, HSQC, and HMBC spectra.

A beech (Fagus sylvatica) sulfite pulp supplied by Lenzing AG, Austria, and a eucalypt (Eucalyptus globulus) kraft pulp obtained from ENCE Group, Spain, were used. Beech sulfite pulp: brightness $88.5 \%$ ISO; kappa number 0.60 ; intrinsic viscosity $843 \mathrm{mg} / \mathrm{mL}$; R18 92\%; crystallinity 0.56 ; monosaccharide composition: glucose $94.07 \pm 0.08$, xylose $3.38 \pm 0.01$, mannose $0.77 \pm 0.003$, arabinose 0.00 , galactose $0.01 \pm 0.001, \quad$ rhamnose $0.00 ; \quad \mathrm{M}_{\mathrm{w}}$ $280 \mathrm{~kg} \mathrm{~mol}^{-1}$. Transition metal content (ICP-MS): Fe: 0.8 ppm, $\mathrm{Cu}: 0.04$ ppm, $\mathrm{M}_{\mathrm{n}} 0.2 \mathrm{ppm},<0.001$ 
ppm for Ag, Au, Pt. Eucalyptus kraft pulp: brightness 86\%ISO; kappa number 0.79 ; intrinsic viscosity $546 \mathrm{mg} / \mathrm{mL}$; R18 93\%; crystallinity 0.48 ; monosaccharide composition: glucose $77.55 \pm 0.12$, xylose $18.45 \pm 0.06$, mannose $0.11 \pm 0.004$, arabinose $0.03 \pm 0.002$, galactose $0.31 \pm 0.001$, rhamnose $0.00 ; \mathrm{M}_{\mathrm{w}} 460 \mathrm{~kg} \mathrm{~mol}^{-1}$. Transition metal content (ICP-MS): $\mathrm{Fe}: 1.5 \mathrm{ppm} \quad \mathrm{Cu}: 0.08 \mathrm{ppm}, \mathrm{Mn}$ : $1.2 \mathrm{ppm},<0.001 \mathrm{ppm}$ for $\mathrm{Ag}, \mathrm{Au}, \mathrm{Pt}$. Intrinsic viscosity was determined as cuen (copper ethylenediamine complex) viscosity according to Ahn et al. (2019), monosaccharide composition by total acid hydrolysis and subsequent analysis of the monosaccharides with anion-exchange chromatography with standard deviation derived from three independent measurements according to Becker et al. (2013), crystallinity by ${ }^{13} \mathrm{C}$ solid-state NMR according to Zuckerstätter et al. (2009), and molecular weight parameters by GPC according to Potthast et al. (2015).

General procedure for reduction of transition metal ions to metal precipitates in NMMO solution

A $50 \mathrm{wt} \%$ aqueous solution of (freshly recrystallized) $\mathrm{N}$-methylmorpholine- $N$-oxide $(50 \mathrm{~mL})$ was blended under stirring with propyl gallate $(0.50 \mathrm{~g}, 2 \mathrm{wt} \%$ rel. to anhydrous NMMO) and cellulosic pulp (air-dried, $2.50 \mathrm{~g}, 5 \%$ rel. to the NMMO solution) for $30 \mathrm{~min}$ at r.t. A transition metal salt (see "Results and discussion" section and Table 1, 500 or $1000 \mathrm{ppm}$ rel. to cellulose, $1.2-10 \mathrm{mg}$ ) was dissolved in stirred bidistilled water $(2.0 \mathrm{~mL})$ at r.t. and NMMO $(2.00 \mathrm{~g})$ was added. This solution was added to the NMMO/PG/ pulp mixtures during $30 \mathrm{~s}$ under stirring. In variations of the procedure, either propyl gallate or cellulosic pulp were omitted or concentrations were changed (see "Results and discussion" section). The mixture was quickly heated to the desired reaction temperature (see "Results and discussion" section) by immersing the reaction vessel into a pre-heated oil bath. After certain reaction intervals, aliquots $(3 \mathrm{~mL})$ were taken and mixed with $20 \mathrm{~mL}$ of bidistilled water under stirring. The precipitated cellulose was collected by filtration and further analyzed by GPC. The liquid phase was used directly for analysis of ions (see below) or extracted with cyclohexane $(3 \times 5 \mathrm{~mL})$. The organic extracts were washed with brine $(2 \times 5 \mathrm{~mL})$, dried over anhydrous $\mathrm{MgSO}_{4}$, and analyzed by GC-MS or TLC.
CAUTION! NMMO mixtures with transition metal ions might undergo violent, explosive reactions with splashing, strong smoke evolvement, charring, and possibly fire. Work only in a well-functioning fume hood and observe all necessary precautionary measures (safety shield, safety goggles, etc.)!

Variations of the general procedure

The general procedures were slightly varied (presence or concentration of components, reaction temperature, reaction time) as described in the main text, schemes, and Table 1. For trapping of intermediary $\mathrm{HOCl} /$ $\mathrm{HOBr}, 3,4$-dehydro- $\alpha$-tocopheryl acetate $(0.1 \mathrm{~g})$ dissolved in 1,4-dioxane (1 mL) was added along with propyl gallate. For the determination of chlorate, the taken reaction aliquots $(3 \mathrm{~mL})$ diluted with bidistilled water $(20 \mathrm{~mL})$ were used. For the direct reaction of NMMO with transition metal ions, the $50 \mathrm{wt} \%$ aqueous NMMO solution was replaced with anhydrous NMMO.

\section{Determination of chlorate in the NMMO solution}

(a) The aqueous solution (ca. $10 \mathrm{~mL}$ ) obtained by dilution of the withdrawn aliquot was filtered to remove cellulose and $2 \mathrm{M}$ aqueous $\mathrm{HNO}_{3}$ was added $(\mathrm{pH} \sim 1)$. Aqueous $\mathrm{AgNO}_{3}$ solution $(0.1 \mathrm{M})$ was added dropwise into the acidified solution under stirring until no further precipitation occurred. The solution was briefly heated (ca. $50{ }^{\circ} \mathrm{C}$ for $1 \mathrm{~min}$ ), the white precipitate $(\mathrm{AgCl})$ was collected by centrifugation and the clear supernatant separated. Aqueous $\mathrm{AgNO}_{3}$ solution $(0.1 \mathrm{M}, 5 \mathrm{~mL})$ and one drop of concentrated $\mathrm{HNO}_{3}$ were added during stirring. The addition of a few drops of saturated aqueous $\mathrm{KNO}_{2}$ solution caused the immediate formation of a white precipitate of $\mathrm{AgCl}$, the chloride being generated in the reduction of chlorate to chloride by nitrite $\left(\mathrm{ClO}_{3}{ }^{-}\right.$ $+3 \mathrm{NO}_{2}^{-} \rightarrow \mathrm{Cl}^{-}+3 \mathrm{NO}_{3}^{-}$).

(b) The aqueous solution obtained by dilution of the withdrawn aliquot (ca. $20 \mathrm{~mL}$ ) was filtered to remove cellulose, diluted to $50 \mathrm{~mL}$ with bidistilled water, mixed with anion exchange resin $\left(2 \mathrm{~g}\right.$, Dowex, $\mathrm{OH}^{-}$form), and gently stirred for $15 \mathrm{~min}$ at r.t. The anion exchanger was collected by filtration, washed with warm ethanol (50 mL, to remove adsorbed NMMO) and bidistilled water $(2 \times 10 \mathrm{~mL})$, and regenerated with $0.1 \mathrm{M}$ aqueous $\mathrm{NaOH}$ solution $(10 \mathrm{~mL})$. The 
Table 1 Platinum salts used for $\operatorname{Pt}(0)$ generation in $50 \mathrm{wt} \%$ aqueous NMMO, and the onset time and temperature of the metal generation in dependence of the presence of propyl gallate $(\mathrm{PG}, 2)$ as NMMO stabilizer

\begin{tabular}{|c|c|c|}
\hline Compound & $2 \% \mathrm{PG}$ as stabilizer added & No PG as stabilizer added \\
\hline Platinum(II) chloride, $\mathrm{PtCl}_{2}$ & r.t., $<30 \mathrm{~min}$ & $90^{\circ} \mathrm{C}, \sim 1 \mathrm{~h}$ \\
\hline Platinum(IV) chloride, $\mathrm{PtCl}_{4}$ & r.t., $<30 \mathrm{~min}$ & $60{ }^{\circ} \mathrm{C},<30 \mathrm{~min}$ \\
\hline trans-Diammindichloroplatinum(II), $\mathrm{Pt}\left(\mathrm{NH}_{3}\right)_{2} \mathrm{Cl}_{2}$ & r.t., $<30 \mathrm{~min}$ & $60^{\circ} \mathrm{C},<30 \mathrm{~min}$ \\
\hline trans-Diammintetrachloroplatinum(IV), $\mathrm{Pt}\left(\mathrm{NH}_{3}\right)_{2} \mathrm{Cl}_{4}$ & r.t., $<30 \mathrm{~min}$ & $60^{\circ} \mathrm{C},<30 \mathrm{~min}$ \\
\hline cis-Diamminetetrachloroplatinum(IV), $\mathrm{Pt}\left(\mathrm{NH}_{3}\right)_{2} \mathrm{Cl}_{4}$ & r.t., $<30 \mathrm{~min}$ & $60{ }^{\circ} \mathrm{C},<15 \mathrm{~min}$ \\
\hline Potassium hexachloroplatinate(IV), $\mathrm{K}_{2} \mathrm{PtCl}_{6}$ & r.t., $<30 \mathrm{~min}$ & $60^{\circ} \mathrm{C},<5 \min$ \\
\hline Potassium hexafluoroplatinate(IV), $\mathrm{K}_{2} \mathrm{PtF}_{6}$ & no reaction up to $100{ }^{\circ} \mathrm{C}$ & no reaction at $115^{\circ} \mathrm{C}$ \\
\hline Potassium hexahydroxidoplatinate(IV), $\mathrm{K}_{2} \mathrm{Pt}(\mathrm{OH})_{6}$ & r.t., $<30 \mathrm{~min}$ & $115^{\circ} \mathrm{C}, \sim 1 \mathrm{~h}$ \\
\hline Platinum(II) nitrate, $\mathrm{Pt}\left(\mathrm{NO}_{3}\right)_{2}$ & r.t., $<30 \mathrm{~min}$ & $115^{\circ} \mathrm{C}, \sim 1 \mathrm{~h}$ \\
\hline Platinum(II) bromide, $\mathrm{PtBr}_{2}$ & r.t., $<30 \mathrm{~min}$ & $90^{\circ} \mathrm{C}, \sim 1 \mathrm{~h}$ \\
\hline Platinum(IV) bromide, $\mathrm{PtBr}_{4}$ & r.t., $<30 \mathrm{~min}$ & $60{ }^{\circ} \mathrm{C},<30 \mathrm{~min}$ \\
\hline trans-Diammintetrabromoplatinum(IV), $\mathrm{Pt}\left(\mathrm{NH}_{3}\right)_{2} \mathrm{Br}_{4}$ & r.t., $<30 \mathrm{~min}$ & $60{ }^{\circ} \mathrm{C},<30 \mathrm{~min}$ \\
\hline cis-Diammintetrabromoplatinum(IV), $\mathrm{Pt}\left(\mathrm{NH}_{3}\right)_{2} \mathrm{Br}_{4}$ & r.t., $<30 \mathrm{~min}$ & $60^{\circ} \mathrm{C},<5 \mathrm{~min}$ \\
\hline
\end{tabular}

$\mathrm{NaOH}$ eluate solution was neutralized with $1 \mathrm{M} \mathrm{HCl}$ and a $1: 1(\mathrm{v} / \mathrm{v})$ mixture of conc. aqueous $\mathrm{MnSO}_{4}$ solution and conc. $\mathrm{H}_{3} \mathrm{PO}_{4}$ was added $(1 \mathrm{~mL})$. The solution turned purple immediately, indicating the presence of $\left[\mathrm{Mn}\left(\mathrm{PO}_{4}\right)_{2}\right]^{3-}$, formed by oxidation of $\mathrm{Mn}^{2+}$ to $\mathrm{Mn}^{3+}$ through chlorate $\left(\mathrm{ClO}_{3}^{-}+6 \mathrm{Mn}^{2+}\right.$ $+12 \mathrm{PO}_{4}{ }^{3-}+6 \mathrm{H}^{+} \rightarrow \mathrm{Cl}^{-}+6\left[\mathrm{Mn}\left(\mathrm{PO}_{4}\right)_{2}\right]^{3-}+3$ $\mathrm{H}_{2} \mathrm{O}$ ). Although NMMO would not interfere with the reaction, it had been completely removed beforehand by the ion exchange/ethanol washing sequence.

Trapping of intermediate $\mathrm{HOCl} / \mathrm{HOBr}$ with vitamin $\mathrm{E}$ derivatives

3,4-Dehydro- $\alpha$-tocopheryl acetate $(0.1 \mathrm{~g})$ dissolved in 1,4-dioxane $(1 \mathrm{~mL})$ was added together with propyl gallate, and the general protocol (see above) was followed. The washed and dried organic extracts were evaporated in vacuo and the mixture was analyzed by TLC. One analytically pure sample was obtained by flash chromatography on silica gel (eluent: toluene). The analytical data of the purified trapping products of $\mathrm{HOCl}$ and $\mathrm{HOBr}$ are given below.

3-Chloro-4-hydroxy- $\alpha$-tocopheryl acetate (7), see also Yokota et al. (2008), TLC (toluene/ $n$-heptane, $\mathrm{v} / \mathrm{v}=1 / 3): R_{F}=0.34 .{ }^{1} \mathrm{H}$ NMR $\delta 2.08\left(\mathrm{~s}, 3 \mathrm{H}, \mathrm{CH}_{3}\right)$, $2.11\left(\mathrm{~s}, 3 \mathrm{H}, \mathrm{CH}_{3}\right), 2.20\left(\mathrm{~s}, 3 \mathrm{H}, \mathrm{CH}_{3}\right), 2.31(\mathrm{~s}, 3 \mathrm{H}$, $\left.\mathrm{CH}_{3} \mathrm{CO}\right), 4.48\left(\mathrm{~d}, 1 \mathrm{H}, 3-\mathrm{CH},{ }^{3} \mathrm{~J}=6.3 \mathrm{~Hz}\right), 5.05 \mathrm{ppm}$ $\left(\mathrm{t}, 1 \mathrm{H}, 4-\mathrm{CH},{ }^{3} \mathrm{~J}=6.3 \mathrm{~Hz}\right) .{ }^{13} \mathrm{C}$ NMR: $\delta$ 12.0, 13.3, $13.7\left(5 \mathrm{a}-\mathrm{CH}_{3}, 7 \mathrm{a}-\mathrm{CH}_{3}, 8 \mathrm{~b}-\mathrm{CH}_{3}\right), 20.3\left(\mathrm{CH}_{3}\right.$ in $\left.\mathrm{OAc}\right)$, 60.3 (3-C), 70.5 (4-C), 77.1 (2-C), 119.3 (4a-C), 123.0 (5-C), 126.1 (7-C), 129.8 (8-C), 147.5 (8a-C), 148.2 (6-C), $169.2 \mathrm{ppm}(\mathrm{C}=\mathrm{O}$ in $\mathrm{Ac})$. Resonances of the isoprenoid side chain are not given. Anal. calcd. for $\mathrm{C}_{31} \mathrm{H}_{51} \mathrm{O}_{4} \mathrm{Cl}$ (523.20): C 71.17, $\mathrm{H}$ 9.83, Cl 6.78, found: C 71.02, H 9.98, Cl 6.54.

3-Bromo-4-hydroxy- $\alpha$-tocopheryl acetate (8), TLC (toluene/ $n$-heptane, v/v $=1 / 3$ ): $R_{F}=0.38 .{ }^{1} \mathrm{H}$ NMR $\delta$ $2.10\left(\mathrm{~s}, 3 \mathrm{H}, \mathrm{CH}_{3}\right), 2.11\left(\mathrm{~s}, 3 \mathrm{H}, \mathrm{CH}_{3}\right), 2.16\left(\mathrm{~s}, 3 \mathrm{H}, \mathrm{CH}_{3}\right)$, $2.30\left(\mathrm{~s}, 3 \mathrm{H}, \mathrm{CH}_{3} \mathrm{CO}\right), 3.72\left(\mathrm{~d}, 1 \mathrm{H}, 3-\mathrm{CH},{ }^{3} \mathrm{~J}=7.0 \mathrm{~Hz}\right)$, $5.02 \mathrm{ppm}\left(\mathrm{t}, 1 \mathrm{H}, 4-\mathrm{CH},{ }^{3} \mathrm{~J}=7.0 \mathrm{~Hz}\right) .{ }^{13} \mathrm{C}$ NMR: $\delta$ 12.4, 13.5, $13.7\left(5 \mathrm{a}-\mathrm{CH}_{3}, 7 \mathrm{a}-\mathrm{CH}_{3}, 8 \mathrm{~b}-\mathrm{CH}_{3}\right), 20.7\left(\mathrm{CH}_{3}\right.$ in OAc), 48.4 (3-C), 68.8 (4-C), 75.6 (2-C), 119.0 (4aC), 123.4 (5-C), 126.4 (7-C), 128.2 (8-C), 146.4 (8aC), 149.0 (6-C), $171.4 \mathrm{ppm}(\mathrm{C}=\mathrm{O}$ in $\mathrm{Ac})$. Resonances of the isoprenoid side chain are not given. Anal. calcd. for $\mathrm{C}_{31} \mathrm{H}_{51} \mathrm{O}_{4} \mathrm{Br}$ (567.64): C 65.59, H 9.06, Br 14.08, found: C 65.65, H 9.29, Br 13.96.

Determination of $\mathrm{N}$-formylmorpholine

A concentrated aqueous solution of the transition metal salts (either $\mathrm{AgNO}_{3}\left(85 \mathrm{mg}, 0.5 \mathrm{mmol}\right.$ ), $\mathrm{PtCl}_{2}$ $(133 \mathrm{mg}, \quad 0.5 \mathrm{mmol})$ or $\mathrm{H}\left[\mathrm{AuCl}_{4}\right] \quad(170 \mathrm{mg}$, $0.5 \mathrm{mmol}$ )) was added to diglyme (bis(2-methoxyethyl)ether, $8 \mathrm{~mL}$ ), and the mixture was heated 
to $120{ }^{\circ} \mathrm{C}$. A solution of NMMO $(0.117 \mathrm{~g}, 1 \mathrm{mmol})$ in diglyme $(1.5 \mathrm{~mL})$ was added very slowly under stirring, stopping the addition immediately if sudden dark discoloration occurred. After addition, the mixture was heated to $130{ }^{\circ} \mathrm{C}$ for $10 \mathrm{~min}$, cooled to room temperature, and poured into diethyl ether $(100 \mathrm{~mL})$. Anhydrous magnesium sulfate $(2 \mathrm{~g})$, as well as activated acidic alumina (5 g, Brockmann grade 1), were added and the mixture was gently stirred at $0{ }^{\circ} \mathrm{C}$ (ice bath) for $30 \mathrm{~min}$. The suspension was transferred into a chromatographic column $(2 \mathrm{~cm}$ i.d.) which was eluted first with diethyl ether (ca. $200 \mathrm{~mL}$ ) and then with warm ethanol $\left(80 \mathrm{~mL}\right.$, ca. $\left.40{ }^{\circ} \mathrm{C}\right)$. The ethanolic phase was evaporated under reduced pressure and the residue was analyzed. $N$-Formylmorpholine (10), b.p. ca. $240{ }^{\circ} \mathrm{C}$, TLC (ethyl acetate): $R_{F}=0.62 .{ }^{1} \mathrm{H}$ NMR $\delta$ $3.35\left(\mathrm{~m}, 2 \mathrm{H}, \mathrm{N}-\mathrm{CH}_{2}\right), 3.52\left(\mathrm{~m}, 2 \mathrm{H}, \mathrm{N}-\mathrm{CH}_{2}\right), 3.61(\mathrm{~m}$, $\left.2 \mathrm{H}, \mathrm{O}-\mathrm{CH}_{2}\right), 3.65$ (m, 3H, O- $\left.\mathrm{CH}_{2}\right), 8.01 \mathrm{ppm}(\mathrm{s}, 1 \mathrm{H}$, $\mathrm{N}-\mathrm{CHO}) .{ }^{13} \mathrm{C}$ NMR: $\delta 40.5\left(\mathrm{~N}-\mathrm{CH}_{2}\right), 45.7\left(\mathrm{~N}-\mathrm{CH}_{2}\right)$, $66.3\left(\mathrm{O}-\mathrm{CH}_{2}\right), 67.3\left(\mathrm{O}-\mathrm{CH}_{2}\right), 160.7 \mathrm{ppm}(\mathrm{N}-\mathrm{CHO})$. Anal. calcd. for $\mathrm{C}_{5} \mathrm{H}_{9} \mathrm{NO}_{2}$ (115.13): C 52.16, H 7.88, N 12.17, found: C 52.03, H 8.14, N 11.96.

Gel permeation chromatography (GPC) and determination of carbonyl and carboxyl group contents

Sample preparation for GPC with fluorescence labeling of carbonyl groups (CCOA method, "carbazole carbonyloxyamine") and fluorescence labeling of carboxyl groups (FDAM method, "fluorenyl diazomethane") was performed as described previously (Röhrling et al. 2002a, b; Potthast et al. 2003; Bohrn et al. 2006; Henniges et al. 2013), with $50 \mathrm{mg}$ of wet samples. In brief, after labeling of the samples, dissolution in $\mathrm{N}, \mathrm{N}$-dimethylacetamide/lithium chloride $9 \%(\mathrm{w} / \mathrm{v})$ was performed after solvent exchange at room temperature. Measurements were performed on a GPC system with multiple detectors (multi-angle laser light scattering (MALLS), refractive index (RI), and fluorescence).

GPC system: fluorescence detectors (TSP FL2000) for CCOA label, Shimadzu RF 535 for FDAM label, MALLS detector: Wyatt Dawn DSP with argon ion laser $\left(\lambda_{0}=488 \mathrm{~nm}\right)$, RI detector: Shodex RI-71. Four serial GPC columns (Polymer Laboratories, PLgel mixed-ALS, $20 \mu \mathrm{m}, 7.5 \times 300 \mathrm{~mm}$ ) were used as the stationary phase. Degasser: Dionex DG-2410, autosampler: HP 1100, pulse damper pump: Kontron pump 420, and column oven: Gynkotek STH 585. Operating conditions: $1.00 \mathrm{~mL} / \mathrm{min}$ flow rate, $100 \mu \mathrm{L}$ injection volume, $45 \mathrm{~min}$ run time, $\lambda_{\mathrm{ex}}=290 \mathrm{~nm} /$ $\lambda_{\mathrm{em}}=340 \mathrm{~nm}$ for CCOA and $\lambda_{\mathrm{ex}}=280 \mathrm{~nm} / \lambda_{\mathrm{em}}$ $=312 \mathrm{~nm}$ for FDAM labels, mobile phase: DMAc/ $\mathrm{LiCl}(0.9 \%$, w/v), filtered through a $0.02 \mu \mathrm{m}$ filter. Data evaluation was performed with standard Chromeleon, Astra, and GRAMS/32 software packages. According to results from standard pulps $(\mathrm{N} \sim 500)$, the standard deviation for carbonyl/carboxyl group determination is below $5 \%$, for $\mathrm{M}_{\mathrm{w}}$ about $5 \%$, and for $\mathrm{M}_{\mathrm{n}}$ around $10 \%$.

\section{Results and discussion}

The initial expectation and hope that the redox processes in the transition metal/NMMO mixtures were always the same-i.e., independent of the metal/ metal salt used-has unfortunately not occurred: apparently, it is a rather dynamic and flexible reaction system. However, this points out all the more how important a detailed characterization of the underlying chemistry can become, not just in mechanistic organic chemistry, but also in material science work. The corresponding studies on the reaction mechanisms are presented below.

1. Elemental silver species on cellulosic substrates

Several procedures have been proposed to synthesize silver nanoparticles in aqueous NMMO and incorporate them into cellulosic fibers (Rac-Rumijowska et al. 2017, 2019,2018; Smiechowicz et al. 2011; Shah et al. 2013). These approaches used $50 \mathrm{wt} \%$ aqueous NMMO stabilized with $2 \%$ propyl gallate. The metal was introduced in the form of aqueous $\mathrm{AgNO}_{3}$ (between 0.04 and $1 \mathrm{M}$ ), which was either added to the pulp or directly into the lyocell spinning dope to get a final Ag concentration of about 250-500 ppm. Blending and dissolution (with concomitant metal precipitate production) were done at $115^{\circ} \mathrm{C}$ for $10 \mathrm{~min}$, followed by dry-wet spinning at the same temperature.

It was logical to assume that in return for the reduction of $\mathrm{Ag}^{+}$ions to elemental silver, functionalities of cellulose would be oxidized, especially the hemiacetals of the reducing ends (which do not have their name for nothing). This would lead to carboxyl 
groups (gluconic acid moiety) at the end of the cellulose chains. Likewise, oxidation of the cellulosic $\mathrm{OH}$ groups along the chains was conceivable, which would lead to keto groups at $\mathrm{C} 2$ and $\mathrm{C} 3$, and aldehyde or carboxyl (glucuronic) functions at C6. Similar reactions between $\mathrm{Ag}^{+}$and cellulose-albeit in the absence of NMMO — had already been used to label the reducing ends of celluloses to prepare silvercontaining cellulosics (Kato 1959; Gagnaire and Vincendon 1973; Kuga and Brown 1988).

The content of oxidized groups in cellulosics and their relation to the molecular weight distribution can be reliably and accurately determined by the CCOA method for carbonyls (Röhrling et al. 2002a, b; Potthast et al. 2003) and the FDAM method for carboxyls (Bohrn et al. 2006), two frequently applied approaches when accurate monitoring of oxidative processes of cellulosics becomes necessary (Potthast et al. 2005). Both rely on group-selective quantitative fluorescence labeling in combination with gel permeation chromatography (Potthast et al. 2015).

While these methods showed a clear oxidative effect of pure NMMO monohydrate on cellulose (120-130 ${ }^{\circ} \mathrm{C}, 2 \mathrm{~h}$ ) accompanied by chain degradation (cf. also Rosenau et al. 2005a, b), no such effects were seen for the silver-containing system, which contained $50 \mathrm{wt} \%$ aqueous NMMO stabilized with $2 \%$ propyl gallate, 5\% cellulosic pulp and $500 \mathrm{ppm}^{+}$(rel. to the pulp, as $1 \mathrm{mM} \mathrm{AgNO}_{3}$ ). Mixing of the reagents occurred at r.t. and the reaction at $50{ }^{\circ} \mathrm{C}$ (see "Materials and Methods" section). Under these conditions, the $\mathrm{C}=\mathrm{O}$ and $\mathrm{COOH}$ content of the cellulose as well as the molecular weight stayed largely unchanged, see Fig. 1. This evidently excluded cellulose as the main reaction partner (= reductant) of the silver ions. Also, the NMMO content remained nearly unchanged, with NMMO consumption by degradation to $\mathrm{N}$-methylmorpholine being below $0.8 \%$. In the absence of silver ions, under otherwise identical conditions, the results were the same as in their presence: almost no introduction of oxidized groups and rather little chain degradation was observed. Oxidation of cellulose was minor and became more pronounced only at temperatures $>120{ }^{\circ} \mathrm{C}$ and reaction times $>1 \mathrm{~h}$.

The actual co-reactant for the silver ions was found more or less by serendipity when we observed a blueblack discoloration at spots of scratching with a metal spatula, which brought propyl gallate (2) back to mind. This compound could not only be a stabilizer that stays in the background and is largely ignored, but it could be as well an active reagent and co-reactant. The observed discoloration was due to gallic acid-iron complexes, which are extremely color-intense. Such compounds have been the basis of inks for centuries, if not millennia, and countless-sometimes rather adventurous - recipes exist for their preparation (Melo et al. 2019; Díaz Hidalgo et al. 2018; Zervos and Alexopoulou 2015). However, all these historic protocols are based on gallic acid (from gall apples) and the addition of iron ions.

When we extracted the reaction mixture with toluene, we found a single reaction product of propyl gallate, namely ellagic acid (4), and a direct linear correlation of its formation with the consumption of $\mathrm{Ag}^{+}$, which indicated a direct conversion and the absence of other parallel or side reactions. Propyl gallate and $\mathrm{Ag}^{+}$were strictly stoichiometrically converted into ellagic acid and elemental $\mathrm{Ag}$ as the final products (Fig. 2, left). Propyl gallate (2\% rel. to aqueous NMMO) was always present in large excess compared to the silver ions (500 ppm rel. to the $5 \mathrm{wt} \%$ dissolved cellulose) so that its concentration could be assumed to remain constant during the reaction. Reaction kinetics, which were recorded at r.t. to slow down the reaction, thus followed a pseudo-first-order with regard to the silver ion concentration and ellagic acid formation. In a reverse experiment-in which an aqueous solution without NMMO being present was used-propyl gallate (2) was added into a tenfold excess of silver ions, giving also a pseudo-first-order kinetics for propyl gallate consumption and ellagic acid (4) formation. This points to the fact that the ratedetermining step is a bimolecular reaction, with its reaction rate $r=\mathrm{d}[4] / \mathrm{dt}=k\left[\mathrm{Ag}^{+}\right][2]$ being first-order with regard to both silver ion concentration and propyl gallate concentration, resulting in overall pseudo-firstorder when either $\mathrm{Ag}^{+}$or $\mathrm{PG}$ are present in large excess, i.e., $r=\mathrm{d}[4] / \mathrm{dt}=k^{\prime}\left[\mathrm{Ag}^{+}\right]=k^{\prime \prime}[2]$, as shown in Fig. 2, right, with $k, k^{\prime}$ and $k^{\prime \prime}$ being the respective kinetic rate constants.

In the first step of the overall redox process, silver ions are reduced by propyl gallate to elemental silver and the corresponding phenoxyl radicals (2a), which immediately recombine to the diphenic acid ester intermediate (3). Mainly entropically driven, this intermediate is immediately converted to ellagic acid and two equivalents of 1-propanol (Scheme 1). The 


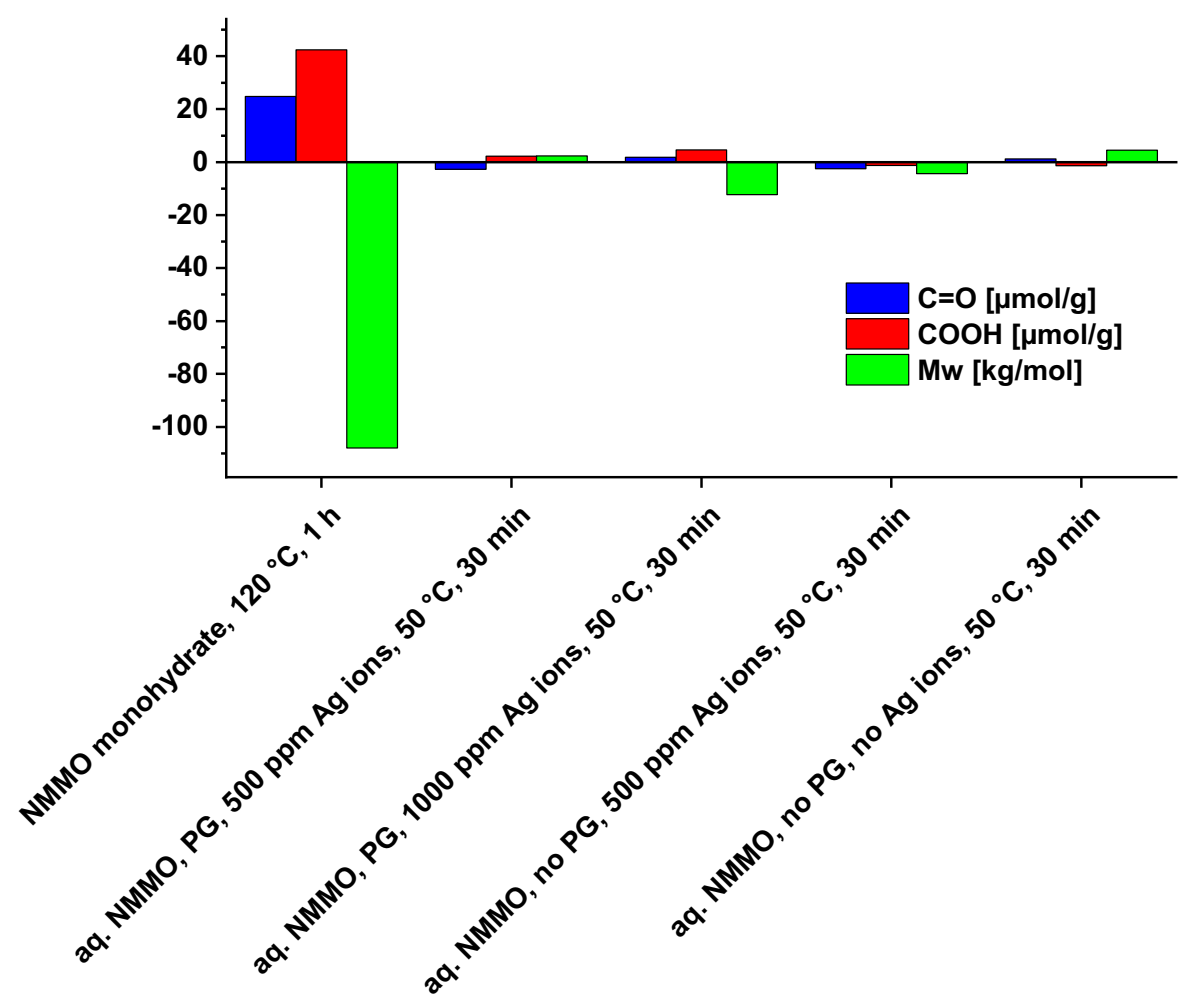

Fig. 1 Changes of carbonyl group content, carboxyl group content, and $\mathrm{M}_{\mathrm{w}}$ of a cellulosic pulp (beech sulfite, $5 \%$ rel. to solvent) upon treatment in different NMMO systems. While NMMO monohydrate treatment at $120{ }^{\circ} \mathrm{C}$ for $1 \mathrm{~h}$ causes a significant introduction of oxidized groups and molecular

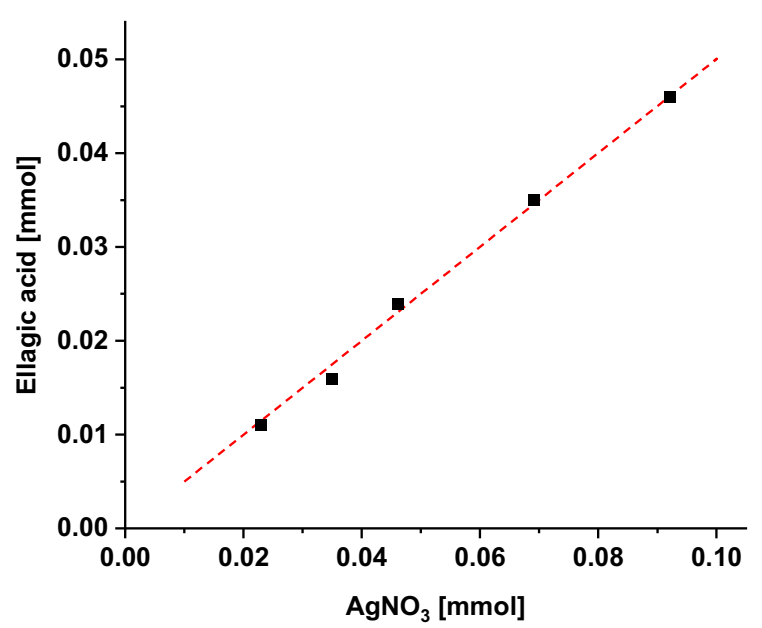

Fig. 2 The reaction of $\mathrm{AgNO}_{3}$ with propyl gallate in $50 \mathrm{wt} \%$ aq. NMMO. Left: 1:2 stoichiometry of the reaction: 1 eq. of ellagic acid formed is formed per 2 eq. of silver ions reduced. The dotted line indicates the 1:2 ratio $(y=0.5 x)$. Right: kinetics of weight loss, the changes are negligibly small in the presence of $\mathrm{Ag}^{+}$at $50{ }^{\circ} \mathrm{C}$ for $30 \mathrm{~min}$, although $\mathrm{Ag}(\mathrm{I})$ was completely reduced to $\operatorname{Ag}(0)$. Values are changes relative to the starting material: $\quad \mathrm{C}=\mathrm{O} \quad 18.3 \mu \mathrm{mol} / \mathrm{g}, \quad \mathrm{COOH} \quad 8.6 \mu \mathrm{mol} / \mathrm{g}, \quad \mathrm{M}_{\mathrm{w}}$ $460 \mathrm{~kg} / \mathrm{mol}$

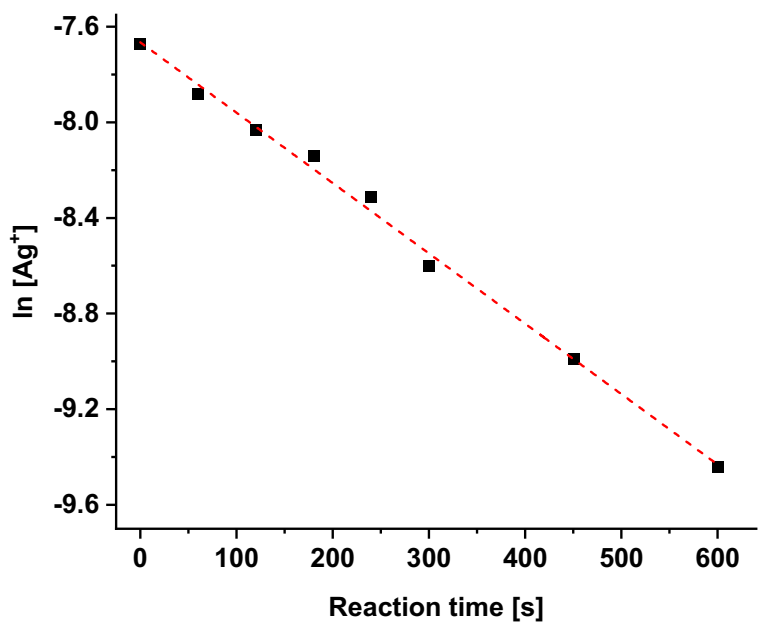

the reaction. The linear relationship between $\ln \left[\mathrm{Ag}^{+}\right]$and reaction time $t$ at $278.15 \mathrm{~K}$ confirms the pseudo-first-order reaction kinetics (dotted line: linear fit, $\mathrm{R}^{2}=0.989$ ) 
redox couple active in this system can thus be summarized with Eq. 1:

$$
\begin{aligned}
& 2 \mathrm{Ag}^{+}+2 \text { Prop }- \text { OGall }+2 \mathrm{H}_{2} \mathrm{O} \\
& \quad \rightarrow 2 \mathrm{Ag}+\text { EllA }+2 \text { Prop }-\mathrm{OH}+2 \mathrm{H}^{+}
\end{aligned}
$$

with Prop-OGall $=$ propyl gallate, Prop-OH $=1$ propanol, and EllA being the common abbreviation of ellagic acid.

The formation of ellagic acid (4) is a typical reaction of gallic acid and its derivatives (AguilarZarate et al. 2018; Jourdes et al. 2012), known for more than a century (Bleuler and Perkin 1916). The analysis of propyl gallate and its reaction products is straightforward as both can be extracted quantitatively with small amounts of toluene (dichloromethane works equally well) followed by determination with GC/MS or HPTLC.

In the absence of propyl gallate, no silver reduction was observed under the applied conditions $\left(50{ }^{\circ} \mathrm{C}\right)$, only to some minor extent after extended reaction times of more than $2 \mathrm{~h}$. At $80^{\circ} \mathrm{C}$, however, the reaction was completed within $30 \mathrm{~min}$ also in the absence of propyl gallate. At the same time, oxidation of cellulose and some chain degradation were observed, which confirmed that cellulose acted as the co-reactant of the silver ions, taking over the usual role of propyl gallate, although requiring harsher conditions (longer reaction times or higher temperatures), see Fig. 3. When also the silver ions were left out (in addition to the absent propyl gallate), these oxidation effects almost vanished, proving that cellulose oxidation under the used conditions was due to the silver ions and not due to NMMO.

2. Elemental platinum species on cellulosic substrates

Platinum nanoparticles have been generated from different platinum salts and precipitated onto cellulosic carriers (Shah et al. 2013), with different temperatures between room temperature and $40{ }^{\circ} \mathrm{C}$ having been used, mainly to adjust the precipitation rate and nanoparticle size. In our experiments, we first used $50 \%$ aqueous NMMO stabilized with $2 \%$ propyl gallate and later the same medium without the PG stabilizer, along with 5\% cellulosic pulp and 1000 ppm (rel. to the pulp) of Pt salt.

For all platinum salts tested (with the only exception of hexafluoroplatinate that did not react at all), the propyl gallate (2) present as a stabilizer of the NMMO acted as the reductant, being converted to ellagic acid (4), see Table 1 , column 2 . The basic redox reaction<smiles>[R10]Oc1c(O)cc(C(=O)OCCC)cc1O[14C](=O)c1cc(O)c(O)c(O)c1-c1c(C(=O)OCCC)cc(O)c(O)c1O</smiles><smiles>CCCCCCCCCCCO</smiles>

Scheme 1 Reduction of silver ions to elemental silver with the lyocell stabilizer propyl gallate (2) being oxidized in turn to ellagic acid (4) via the corresponding phenoxyl radical intermediates (2a) and diphenic acid bis(n-propyl) ester (3) 


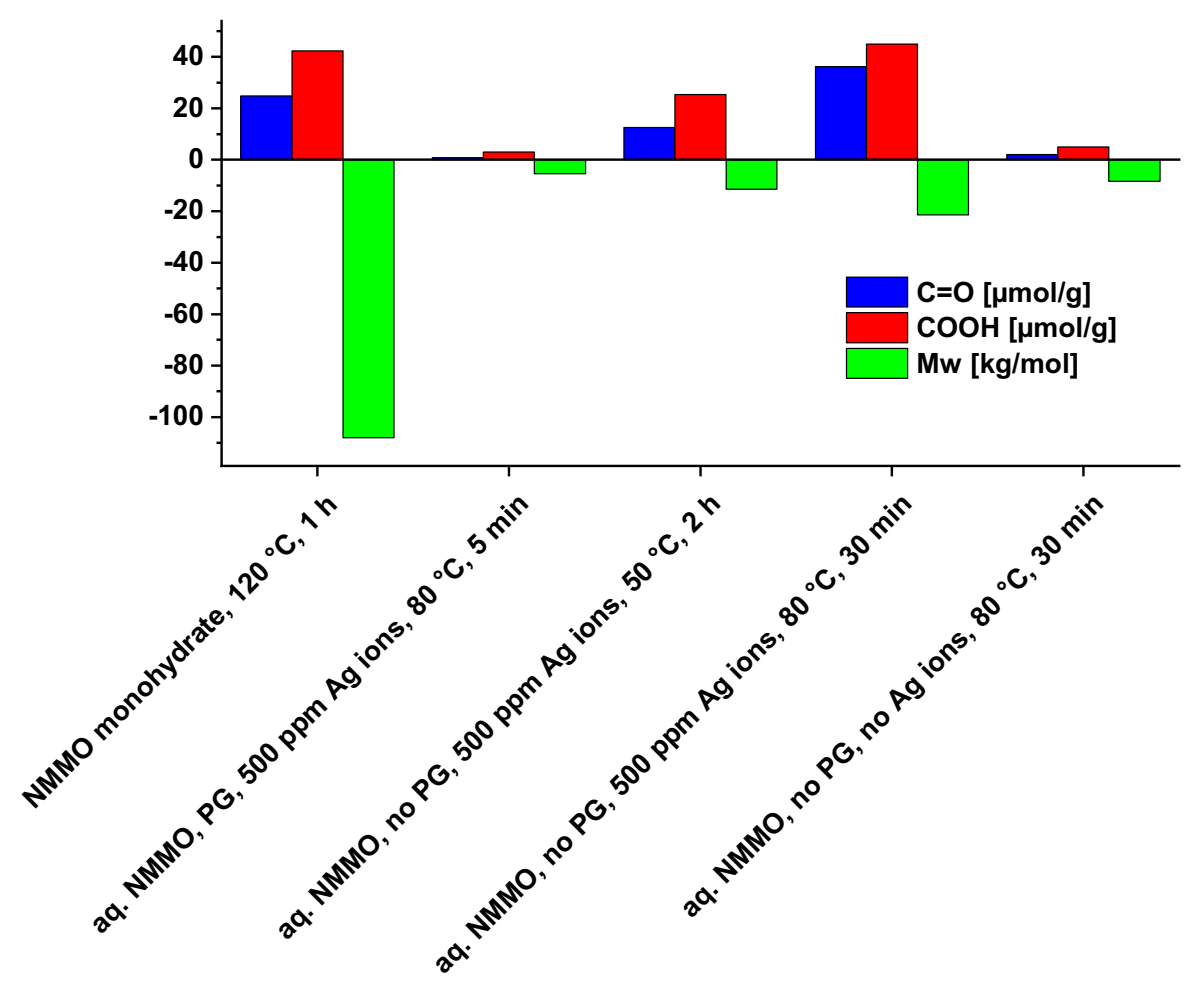

Fig. 3 Changes of carbonyl group content, carboxyl group content, and $\mathrm{M}_{\mathrm{w}}$ of a cellulosic pulp (beech sulfite, $5 \%$ rel. to solvent) upon treatment in different NMMO systems. In the absence of propyl gallate, cellulose takes over the role of the

was thus analogous to the silver case (see also Scheme 1). However, the reduction of the platinum ions proceeded much faster than that of $\mathrm{Ag}^{+}$. It occurred already at room temperature, while for $\mathrm{Ag}^{+}$ temperatures around $80-100{ }^{\circ} \mathrm{C}$ were required. Also the stoichiometry of the reaction was obviously different: while for silver a ratio of $1: 1$ between $\mathrm{Ag}^{+}$ and PG was required (corresponding to $\mathrm{Ag}$ : ellagic acid $=2: 1$, see Fig. 2, left), the stoichiometric ratio Pt:PG was 1:2 for Pt(II) and 1:4 for Pt(IV) salts, corresponding to Pt: ellagic acid $=1: 1$ for $\mathrm{Pt}(\mathrm{II})$ and 1:2 for Pt(IV), respectively. Differences in the reactivity of the salts at room temperature were not observed, and the reaction did not change at all when no cellulose was present.

With the same abbreviations as used above (PropOGall for propyl gallate, Prop-OH for $n$-propanol, and EllA for ellagic acid), the general redox system for $\mathrm{Pt}(\mathrm{II} / \mathrm{IV})$ and propyl gallate can be summarized by Eqs. 2 and 3, respectively: reductant of silver ions, but more drastic conditions are required for the reduction to proceed. Values are changes relative to the starting material: $\mathrm{C}=\mathrm{O} 18.3 \mu \mathrm{mol} / \mathrm{g}, \mathrm{COOH} 8.6 \mu \mathrm{mol} / \mathrm{g}, \mathrm{M}_{\mathrm{w}}$ 460 kg/mol (cf. Fig. 1)

$$
\begin{aligned}
& \mathrm{Pt}^{2+}+2 \text { Prop }- \text { OGall }+2 \mathrm{H}_{2} \mathrm{O} \\
& \quad \rightarrow \operatorname{Pt}(0)+\text { EllA }+2 \text { Prop }-\mathrm{OH}+2 \mathrm{H}^{+} \\
& \mathrm{Pt}^{4+}+4 \text { Prop }- \text { OGall }+4 \mathrm{H}_{2} \mathrm{O} \\
& \quad \rightarrow \operatorname{Pt}(0)+2 \text { EllA }+4 \text { Prop }-\mathrm{OH}+4 \mathrm{H}^{+} .
\end{aligned}
$$

In the absence of propyl gallate, the reduction to elemental platinum required significantly higher temperatures, a fact that has been overlooked so far. The precipitation of elemental $\mathrm{Pt}$ commenced around $60{ }^{\circ} \mathrm{C}$ for the platinum(diammin)-complexes and $\mathrm{Pt}(\mathrm{IV})$ halides, and at $90{ }^{\circ} \mathrm{C}$ for the tested $\mathrm{Pt}(\mathrm{II})$ halides, see Table 1, column 3. Similar to the PG-case, hexafluoroplatinate (IV), which is known to be an exceptionally stable platinum complex (Holleman and Wiberg 1985b), did not react at all, but also hexahydroxidoplatinate(IV), which reacted well with $\mathrm{PG}$, showed no reaction in its absence (except at high temperature). Once more the results were the same independent of whether cellulose was present or not. Obviously, when the easy-to-oxidize PG was lacking, 
the system had to swerve and use a less "convenient" reductant. For all chloride-containing platinum salts, chlorate $\left(\mathrm{ClO}_{3}{ }^{-}\right)$was found as one reaction product, for which the chloride in the starting material was obviously the only source. The presence of chlorate was confirmed by ion chromatography and precipitation (see "Materials and Methods" section); other Clbased anions apart from chloride itself (chlorite and perchlorate), were absent. Since neither Pt(II) nor $\mathrm{Pt}(\mathrm{IV})$ oxidizes chloride to chlorate directly (otherwise the respective salts would not be stable), an involvement of NMMO was indicated, and indeed, the formation of equivalent amounts of $\mathrm{N}$-methylmorpholine (NMM, 5), the deoxygenation product of NMMO, was observed, see Fig. 4 and Scheme 2. Therefore, three parallel processes seemed to be operative in the reaction system, the reduction of the platinum ions to elemental metal, oxidation of chloride, and reduction of NMMO (1) to NMM (5).

Such oxidation of halides by NMMO has been observed for the first time in the reaction of cyanuric chloride with NMMO (Rosenau et al. 2002a,b) and later also for gold complexes in the presence of NMMO monohydrate (Kitaoka et al. 2011). In both cases, chlorate was the final product, which was formed as a disproportionation product of initially generated hypochlorite $\left(\mathrm{HOCl} / \mathrm{ClO}^{-}\right)$. Therefore, we assumed that a similar mechanism was also operative in the present case of the Pt salts. Indeed, the addition of the HOCl-trapping agent 3,4-dehydro- $\alpha$-tocopheryl acetate (6) to the reaction system (platinum salt, $50 \%$ aqueous NMMO, $60{ }^{\circ} \mathrm{C}$, no propyl gallate) afforded the trapping product of hypochlorous acid $(\mathrm{HOCl})$, chlorohydrin 3-chloro-4-hydroxy- $\alpha$-tocopheryl

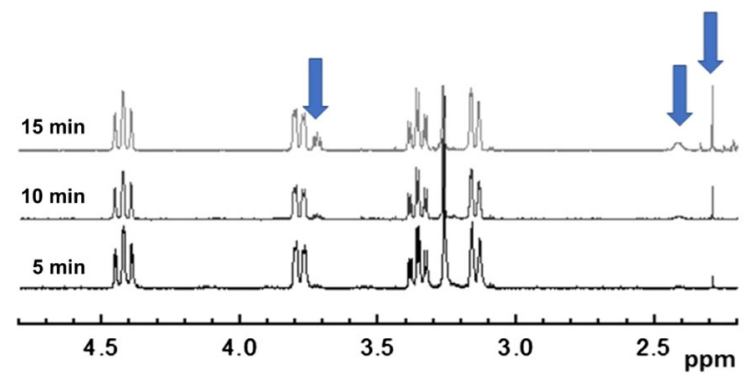

Fig. 4 The relevant section of ${ }^{1} \mathrm{H}$ NMR spectra of NMMO solutions after reaction with $\mathrm{PtCl}_{4}$ at r.t. for different times. The appearing resonances of $\mathrm{N}$-methylmorpholine (5) are indicated by arrows $\left(\delta 2.29\left(\mathrm{~N}-\mathrm{CH}_{3}\right), 2.41\left(\mathrm{~N}-\mathrm{CH}_{2}\right)\right.$, and $3.72 \mathrm{ppm}(\mathrm{O}-$ $\left.\mathrm{CH}_{2}\right)$ ). All other resonances belong to NMMO acetate (7), almost quantitatively (Scheme 2). The situation was analogous in the case of bromide salts (see Table 1), with intermediate hypobromite being trapped by trapping agent (6) as 3-bromo-4-hydroxy$\alpha$-tocopheryl acetate (8) in $64 \%$ yield. The advantage of this trapping reagent and its trapping products is their very high lipophilicity due to the isoprenoid $\mathrm{C}_{16} \mathrm{H}_{33}$ side chain, which renders them extremely well extractable with $n$-hexane, also from very complex multi-component mixtures, and easily analyzable.

With the intermediacy of $\mathrm{HOCl}$ confirmed, the corresponding redox system can be characterized in a way that in the overall process $\mathrm{Pt}(\mathrm{II} / \mathrm{IV})$ is reduced to $\operatorname{Pt}(0)$ while chloride is oxidized to chlorate. In detailed steps, $\mathrm{Pt}(\mathrm{II} / \mathrm{IV})$ is reduced to elemental platinum and $\mathrm{Cl}^{-}$is oxidized, in turn, to $\mathrm{ClO}^{-}$(Scheme 2, red). At the same time, NMMO is reduced to NMM (Scheme 2, blue). This is followed immediately by the disproportionation of the formed hypochlorite into chloride and chlorate, which is a kinetically and thermodynamically highly favored process (Holleman and Wiberg 1985a). Note that the two reduction processes - that of $\mathrm{Pt}(\mathrm{II} / \mathrm{IV})$ and that of NMMO - are not independent: neither $\mathrm{Pt}(\mathrm{II} / \mathrm{IV}$ ) alone nor NMMO alone is reduced by chloride, but in combination, they are obviously sufficiently reactive. Coulombic interaction of the negative exo-oxygen in NMMO with transition metals is known to increase the length of the highly polar $\mathrm{N}-$ $\mathrm{O}$ bond and to render that bond less stable (Linton 1940). Thus, it represents the first step of transition metal ion-induced $\mathrm{N}-\mathrm{O}$ bond cleavage (Rosenau et al. 2001). It is reasonable to assume that a similar NMMO-metal interaction is also present in the PtNMMO-Cl system. In any case, NMMO would be required to enter the coordination sphere of the $\mathrm{Pt}$ cations for the reaction to occur.

The overall redox reaction of $\mathrm{Pt}(\mathrm{II})$ salts can thus be described by Eqs. 4-6 and those of Pt(IV) salts by Eqs. 7-9, cf. Scheme 2. Equations 4 and 7 describe the actual redox process under the generation of hypochlorite, Eqs. 5 and 8 represent the immediate disproportionation of hypochlorite, and Eqs. 6 and 9 give the resulting net process (the starting salts are written in their non-dissociated form for clarity). With regard to all $\mathrm{Pt}$ reactions with chloride, the situation is fully analogous for the bromide case. 


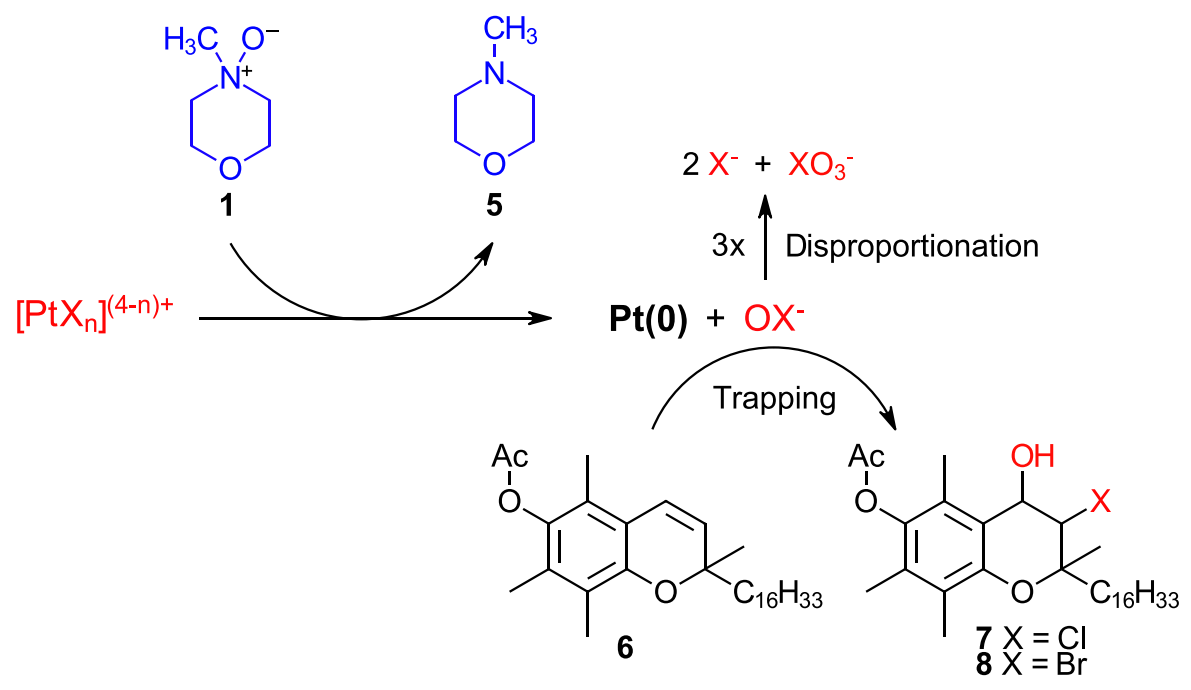

Scheme 2 Reduction of platinum(IV) ions to elemental platinum. At the same time, chloride/bromide ions are being oxidized to hypochlorite/hypobromite, which was confirmed by trapping reactions with a tocopherol (vitamin E) derivative (6), and NMMO (1) is in turn reduced to NMM (5). The hypohalite

$\mathrm{PtCl}_{2}+\mathrm{NMMO}+\mathrm{H}_{2} \mathrm{O}$

$\rightarrow \mathrm{Pt}+\mathrm{NMM}+2 \mathrm{HOCl}$

$3 \mathrm{ClO}^{-} \rightarrow 2 \mathrm{Cl}^{-}+\mathrm{ClO}_{3}^{-}$

$3 \mathrm{PtCl}_{2}+3 \mathrm{NMMO}+3 \mathrm{H}_{2} \mathrm{O}$

$\rightarrow 3 \mathrm{Pt}+3 \mathrm{NMM}+2 \mathrm{HClO}_{3}+4 \mathrm{HCl}$

$\mathrm{PtCl}_{4}+2 \mathrm{NMMO}+2 \mathrm{H}_{2} \mathrm{O}$

$\rightarrow \mathrm{Pt}+2 \mathrm{NMM}+4 \mathrm{HOCl}$

$3 \mathrm{ClO}^{-} \rightarrow 2 \mathrm{Cl}^{-}+\mathrm{ClO}_{3}^{-}$

$3 \mathrm{PtCl}_{4}+6 \mathrm{NMMO}+6 \mathrm{H}_{2} \mathrm{O}$

$\rightarrow 3 \mathrm{Pt}+6 \mathrm{NMM}+4 \mathrm{HClO}_{3}+8 \mathrm{HCl}$

Interestingly, there was a distinct reactivity difference between $\mathrm{Pt}$ salts that have chloro ligands, i.e. chloride in the coordination space sphere of $\mathrm{Pt}$, and those salts in which chloride is the counter anion. The former reacted much more readily (see Table 1): at $60{ }^{\circ} \mathrm{C}$ the reaction was complete within less than $30 \mathrm{~min}$. In the case of $\left[\mathrm{PtCl}_{6}\right]^{2-}$ as the most reactive complex salt tested (Table 1) the reaction was even complete after 5 min. In the case of $\mathrm{PtCl}_{2}$ and $\mathrm{PtBr}_{2}-$ with halides being present as anions and $\mathrm{Pt}$ in solution in the form of the aqua-complexes $\left[\mathrm{Pt}\left(\mathrm{H}_{2} \mathrm{O}\right)_{4}\right]^{2+}$ and undergoes immediate disproportionation into chloride and chlorate (bromide and bromate) which are found as stable halide-derived species after the reaction. The reactions of platinum(II) would be analogous

$\left[\mathrm{Pt}\left(\mathrm{H}_{2} \mathrm{O}\right)_{6}\right]^{2+}$ - the reaction at $90{ }^{\circ} \mathrm{C}$ was still incomplete after $1 \mathrm{~h}$.

It is known that platinum complexes can undergo ligand isomerism (Kukushkin 1991). Either ligands change places within the coordination sphere or there is an exchange between ligands and counterions. Such isomerism is too unfavorable at room temperature but becomes more prominent at higher temperatures. In water both aqua- and hydroxido-complexes can occur depending on $\mathrm{pH}$ and concentrations. The fact that the exceptionally stable $\left[\mathrm{PtF}_{6}\right]^{2-}$, which does not undergo ligand exchange at all, is not reduced in the NMMO system-even if excess chloride is added to the solution-might be an indication that only $\mathrm{Cl}^{-}$in the coordination sphere of the central metal ion, i.e., as a chloro ligand, can undergo a reaction according to Eqs. 6 or 9, but not chloride outside the ligand shell. If this is correct, the slower reactivity of some salts could be readily explained by the ligand-anion isomerism: the freely mobile chloride anions must first be immobilized and coordinated to the central cation before they become amenable to the oxidation process. This interesting detail of platinum salt reactivity is currently investigated in more detail, especially concerning the question of whether cis- and transcomplexes (Holleman and Wiberg 1985b) can be distinguished by reactivity differences towards 
NMMO or not, which is of interest in view of analytics of cisplatin-type chemotherapeutics. Table 1 seems to indicate that the chloro ligands in cis-Pt complexes reacted faster than in the trans-counterparts.

From the viewpoint of material science, a large number of suitable platinum salts are placed at disposal to generate the corresponding Pt particles, and the different reactivities could allow adjustments of kinetics and properties. Still, the mechanistic question remained how platinum salts would react that do not provide halide ions as co-reactants, neither in the coordination sphere nor as counteranions. We addressed this question by means of $\operatorname{Pt}\left(\mathrm{NO}_{3}\right)_{2}$, $\left[\mathrm{PtF}_{6}\right]^{2+}$ and $\left[\mathrm{Pt}(\mathrm{OH})_{6}\right]^{2+}$, both as the respective potassium salts (Table 1). While the fluoro-complex showed no reactivity at all, the hydroxido-complex and the platinum nitrate reacted slowly at $115{ }^{\circ} \mathrm{C}$ and caused concomitant oxidation of cellulose parallel to $\mathrm{Pt}(0)$ generation, see Fig. 5. The reaction of Pt salts with cellulose in $50 \mathrm{wt} \%$ aqueous NMMO in the absence of chloride was thus analogous to that of silver salts in the absence of propyl gallate (see Fig. 1).
3. Elemental gold species on cellulosic substrates

The generation of elemental gold in aqueous NMMO follows the same reaction pathways as in the cases of $\mathrm{Ag}$ and Pt. In our work, the starting gold complex was tetrachloroaurate(III), in the form of chloroauric acid $\mathrm{H}\left[\mathrm{AuCl}_{4}\right]$, similar to literature accounts (Yokota et al. 2008; Kitaoka et al. 2011). In $50 \mathrm{wt} \%$ aqueous NMMO stabilized by $2 \%$ propyl gallate (2), $\mathrm{Au}(\mathrm{III})$ was neatly reduced to elemental $\mathrm{Au}(0)$ at $50{ }^{\circ} \mathrm{C}$ while ellagic acid (4) was formed in turn. This is analogous to the reaction as shown in Scheme 1 for $\mathrm{Ag}^{+}$and propyl gallate. In the absence of propyl gallate, the system once again took the "chloride pathway" described above for the Pt case, and chloride was oxidized to intermediate hypochlorite, which immediately underwent disproportionation into chloride and chlorate, $\mathrm{cf}$. Scheme 2 . The reaction in 50\% aqueous NMMO was completed within $5 \mathrm{~min}$ at $80{ }^{\circ} \mathrm{C}$, whereas the literature listed conditions of $80 \%$ aqueous NMMO at $100{ }^{\circ} \mathrm{C}$, under which the presence of $\mathrm{HOCl}$ as an intermediate had been detected by trapping (Yokota et al. 2008). Therefore,

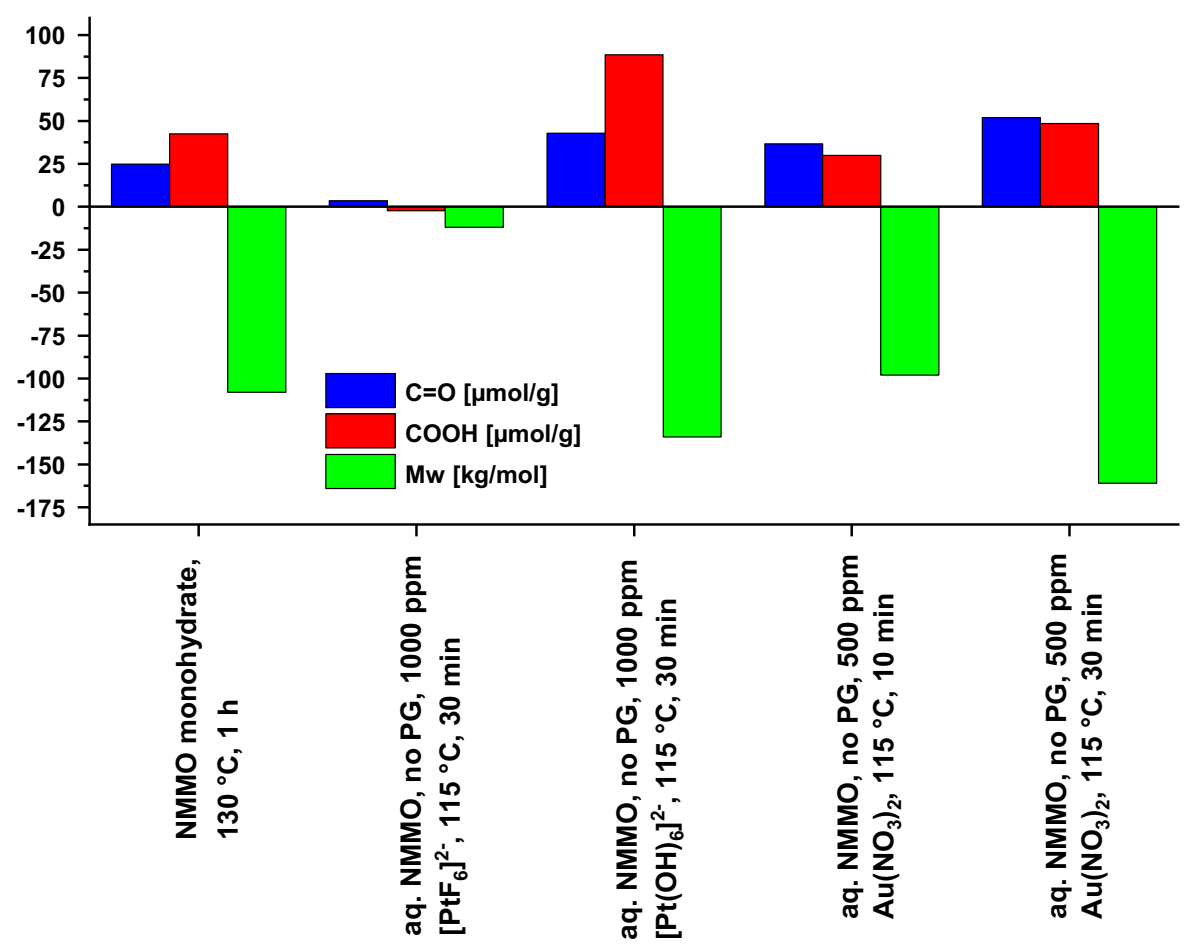

Fig. 5 Changes of carbonyl group content, carboxyl group content, and $\mathrm{M}_{\mathrm{w}}$ of a cellulosic pulp (beech sulfite, $5 \%$ rel. to solvent) upon treatment in different NMMO systems. In the absence of propyl gallate, cellulose takes over the role of the reductant of platinum or gold ions but requires more drastic conditions. Values are relative changes referring to the starting material: $\quad \mathrm{C}=\mathrm{O} \quad 18.3 \mu \mathrm{mol} / \mathrm{g}, \quad \mathrm{COOH} \quad 8.6 \mu \mathrm{mol} / \mathrm{g}, \quad \mathrm{M}_{\mathrm{w}}$ 460 kg/mol (cf. Fig. 1) 
a repetition of this trapping experiment was not considered necessary in our case because of the only slightly differing conditions. The overall reaction can be described by Eqs. 10-12, in analogy to the above Pt case (Scheme 2).

$$
\begin{aligned}
& 2 \mathrm{HAuCl}_{4}+5 \mathrm{NMMO}+3 \mathrm{H}_{2} \mathrm{O} \\
& \rightarrow 2 \mathrm{Au}+5 \mathrm{NMM}+8 \mathrm{HOCl} \\
& 3 \mathrm{ClO}^{-} \rightarrow 2 \mathrm{Cl}^{-}+\mathrm{ClO}_{3}^{-} \\
& 6 \mathrm{HAuCl}_{4}+15 \mathrm{NMMO}+9 \mathrm{H}_{2} \mathrm{O} \\
& \rightarrow 6 \mathrm{Au}+15 \mathrm{NMM}+8 \mathrm{HClO}_{3}+16 \mathrm{HCl}
\end{aligned}
$$

Chloride was present as chloro-ligand in the coordination shell of the central $\mathrm{Au}^{3+}$, whichaccording to the above hypothesis of reactive chloroligands and non-reactive chloride anions-would render it amenable to the redox process.

In the case of $\mathrm{Au}\left(\mathrm{NO}_{3}\right)_{3}$ as the $\mathrm{Au}^{3+}$ source, i.e. $\mathrm{Cl}^{-}$ being absent, no reaction was observed at $80{ }^{\circ} \mathrm{C}$, but it started at $115{ }^{\circ} \mathrm{C}$. This reaction behavior was thus completely analogous to the Pt case. It was somewhat faster, however, showing complete consumption already after approx. $10 \mathrm{~min}$, while the Pt reduction needed about $30 \mathrm{~min}$. With the absence of chloride as the co-reactant, cellulose became the reductant also in the $\mathrm{Au}$ case, and this process was once again monitored by following the increase of carbonyl and carboxyl moieties in the polysaccharide (Fig. 5). Also here, the reaction did not stop when the concentration of metal ions was higher than the approximate amount of reducing ends in cellulose, which means that evidently also cellulosic hydroxyl groups were oxidized. These hydroxyl groups are converted to carbonyl structures at $\mathrm{C} 2, \mathrm{C} 3$, or $\mathrm{C} 6$, while reducing ends (and some carbonyls at C6) afford carboxylic acid moieties upon oxidation.

\section{Transition metal species from aqueous NMMO solutions in the absence of cellulose}

From the previous experiments we have learned that different chemical species can act as reductants towards the transition metal ions under lyocell (aqueous NMMO) conditions: either propyl gallate, chloroligands or cellulose. But how does the system behave chemically when neither of these three co-reactants is available, i.e. if only the transition metal salt and aqueous NMMO are present? The answer could not be clearly extracted from the literature, since the description of the exact mixture of the composition is sometimes rather vague. After all, the methods described were aimed at the nanoparticles produced and their properties rather than at an accurate chemical and mechanistic description of the redox systems involved.

It is known that the interaction of transition metal ions and NMMO, also as an aqueous solution, can cause exothermicity and explosions due to the autocatalytic decay of NMMO if NMMO is present in excess (Rosenau et al. 1999). Transition metal ions can also be used to degrade equivalent amounts of amine $\mathrm{N}$-oxides under controlled conditions, which can be used for synthetic purposes (Dasgupta and Donaldson 1998; Coleman et al. 2000; Gomes and Antunes 2001; Rosenau et al. 2004). We, therefore, used a concentrated aqueous solution of the transition metal salts $\left(\mathrm{AgNO}_{3}, \mathrm{PtCl}_{2}\right.$, and $\left.\mathrm{H}\left[\mathrm{AuCl}_{4}\right]\right)$ in diglyme (2.5 wt\%) to which NMMO in the same solvent was very slowly added at $120{ }^{\circ} \mathrm{C}$ to take advantage of the dilution effect and render the reaction controllable. The reaction was immediately recognizable by a color change due to the precipitated (nano)particulate metals. The metal ions were always present in excess because the small amounts of added NMMO reacted immediately and could not accumulate. Analysis of the mixture showed-independent of the metal involved-only one single NMMO-derived reaction product, namely $N$-formylmorpholine (10), apart from less than $5 \%$ of $N$-methylmorpholine $(\mathbf{5})$. The ${ }^{1} \mathrm{H}$ and ${ }^{13} \mathrm{C}$ NMR spectra of compound $\mathbf{1 0}$ are shown in Fig. 6. Note that the free rotation of the $\mathrm{C}-\mathrm{N}$ amide bond is restricted at room temperature due to its partial double bond character, which renders the two "sides" of the morpholine ring magnetically inequivalent so that two ${ }^{13} \mathrm{C}$ resonances appear for the two $\mathrm{N}-\mathrm{CH}_{2}$ moieties and also two for the two $O$-methylene groups. Increasing the measurement temperature would diminish the shift difference, and at the coalescence temperature $T_{c}$, when the $\mathrm{C}-\mathrm{N}$ bond rotation becomes fast on the NMR time scale, the two separated peaks would coincide. This is similar to the cellulose solvent $N, N$-dimethylacetamide, which also shows restricted $\mathrm{C}-\mathrm{N}$ bond rotation at room temperature, and the determination of the activation barrier of this bond rotation based on the NMR coalescence temperature (Chrapava et al. 2003). 

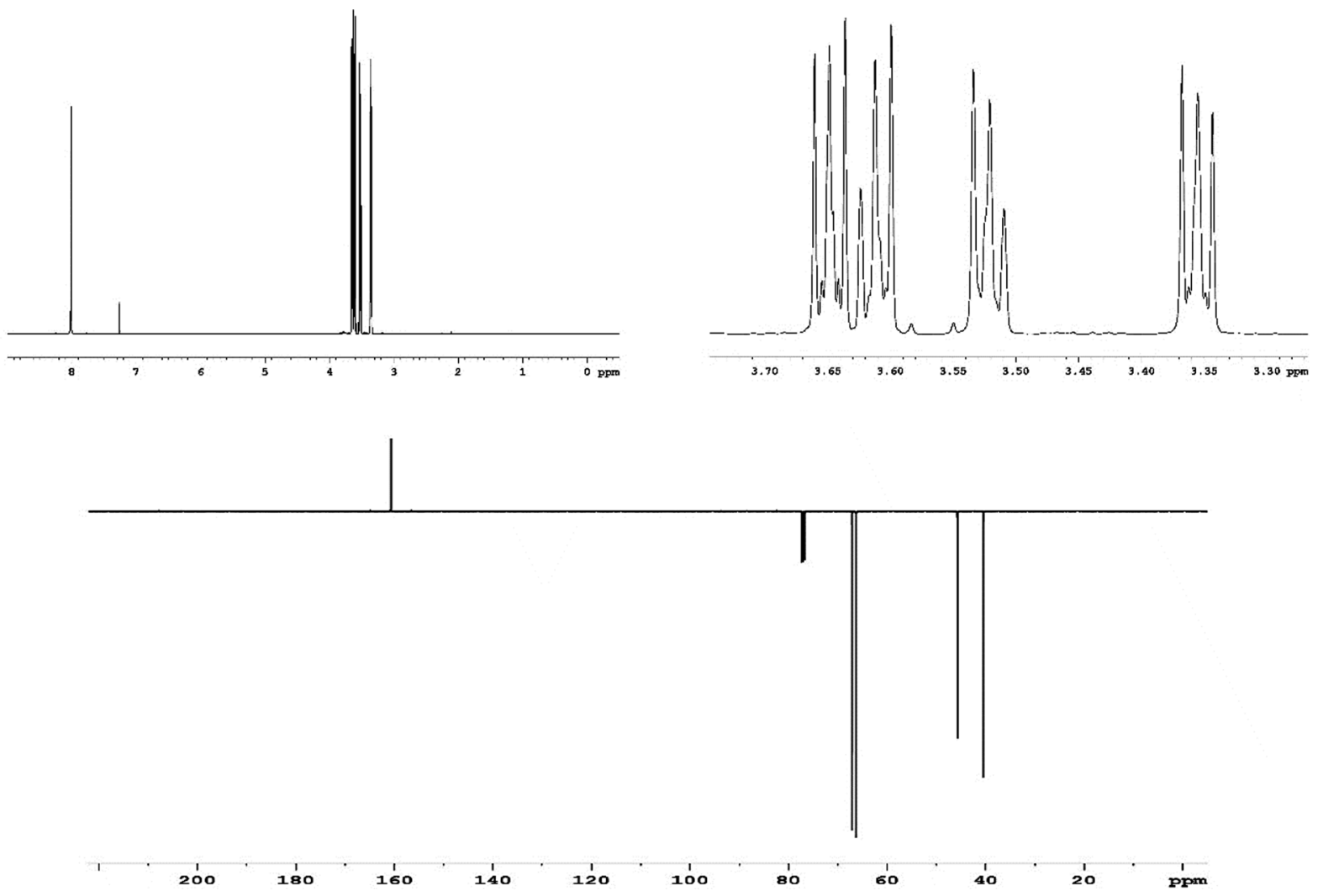

Fig. $6 \mathrm{NMR}$ spectra of $\mathrm{N}$-formylmorpholine (10) in $\mathrm{CDCl}_{3}$. Top left: ${ }^{1} \mathrm{H}$ NMR, survey spectrum; top right: ${ }^{1} \mathrm{H}$ NMR, zoom of the methylene region between 3 and 4 ppm; bottom: ${ }^{13} \mathrm{C}$

This compound was evidently an oxidation product of the intermediate $\mathrm{N}$-(methylene)morpholinium ions (11) and $N$-hydroxymethylmorpholine (Scheme 3), which are in equilibrium with each other. They both are carriers of the autocatalytic NMMO degradation (Scheme 3, red). The fact that mixing the reagents in an opposite way-i.e. addition of the transition metal salt solution into excess NMMOcaused an immediate violent reaction under reboiling, accompanied by black discoloration of the mixture and complete NMMO consumption, but without significant metal ion reduction, is an indirect proof of their formation. $\mathrm{N}$-Hydroxymethylmorpholine (12) represents a hemiaminal of formaldehyde, which is a very strong reducing species and is readily further oxidized to the carboxylic stage (formic acid) (Potthast et al. 2000). Under the conditions used, we observed neither further oxidation of the formyl moiety to $\mathrm{CO}_{2}$, which would leave the remaining
NMR, survey spectrum. Solvent signals: $7.26 \mathrm{ppm}\left({ }^{1} \mathrm{H}, \mathrm{CHCl}_{3}\right.$ trace) and triplet at $77.0 \mathrm{ppm}\left({ }^{13} \mathrm{C}, \mathrm{CDCl}_{3}\right)$

morpholine part detectable, nor hydrolysis of $\mathrm{N}$ formylmorpholine into morpholine and formic acid.

Thus, the direct redox reaction of transition metal ions with NMMO is possible, but not NMMO itself is the corresponding reductant, but NMMO-derived intermediates, which are formed through the interaction of NMMO with the metal ions. If carried out cautiously, the process is astonishingly neat, and $N$ formylmorpholine is formed nearly quantitatively as the sole NMMO-derived product. However, the reaction cannot be conducted under the usual conditions used for metal particle precipitation on celluloses, as only NMMO degradation and no metal ion reduction would occur. Under the quite drastic conditions required (no aqueous dilution, temperatures of $130{ }^{\circ} \mathrm{C}$ ) NMMO has always to be the deficient reagent with the metal ions present in excess, otherwise, the NMMO present will immediately be autocatalytically degraded without the metal ions being reduced. 


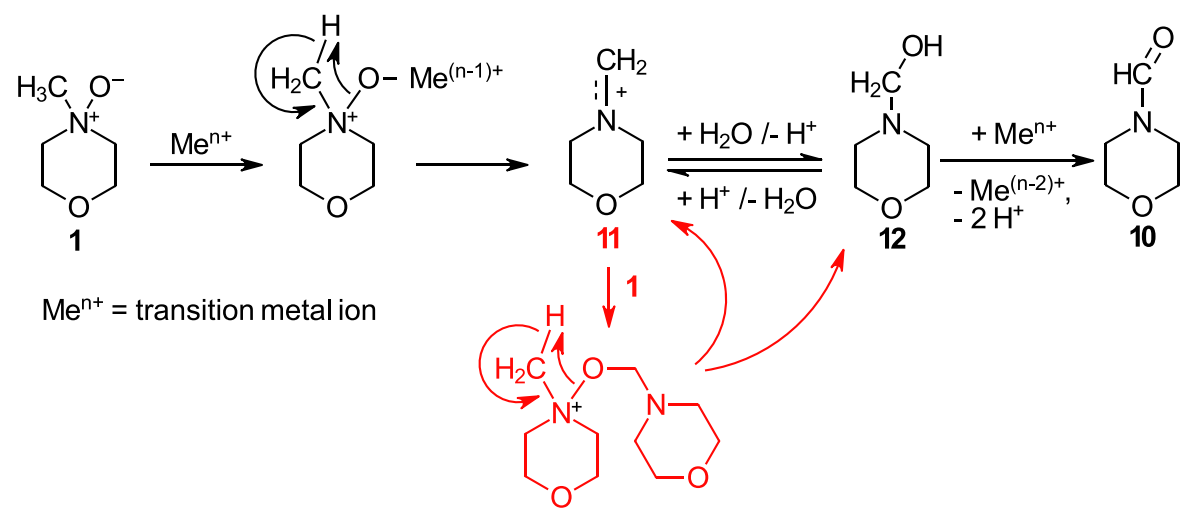

Scheme 3 Direct reaction of transition metal ions (excess) with NMMO monohydrate (1) at elevated temperatures: the intermediate, NMMO-derived $N$-(methylene)morpholinium ions (11) react with water to $N$-hydroxymethylmorpholine (12), which is oxidized to $N$-formylmorpholine (10) as the final

\section{Conclusions}

Addressing the exemplary cases of elemental Ag, Pt, and $\mathrm{Au}$ particles generated from the corresponding salts in aqueous NMMO, we have observed that different chemical species were able to take the role of the co-reacting reductants. The strong oxidant NMMO itself, as introductorily mentioned, is evidently unable to act directly in this way. However, it can still be chemically involved in the conversion, not just being present as the reaction medium or as a swelling agent. Upon comparison of the reaction rates of the coreacting reductants for the metal ions, a reactivity order was obvious which was the same for all three transition metals tested: propyl gallate $>>$ chloride $>$ cellulose .

In the presence of the common NMMO stabilizer propyl gallate $(\mathrm{PG}, \mathbf{1})$, the latter is readily oxidized to ellagic acid (4) and the metal ions are reduced (Scheme 1). Neither NMMO nor cellulose are affected in this process, which proceeded already at room temperature or temperatures below $50{ }^{\circ} \mathrm{C}$. If $\mathrm{PG}$ is absent, chloride ions will become part of the redox pair, being oxidized to $\mathrm{HOCl}$, while both metal ions and NMMO are reduced (Scheme 2). This process requires temperatures between 60 and $80{ }^{\circ} \mathrm{C}$ to be completed in less than $30 \mathrm{~min}$. Also, here, cellulose integrity is not compromised. If also chloride is absent, cellulose itself can act as the co-reactant, and carbonyl functions are introduced while the metal ions are reaction product, while the transition metal ions are reduced to elemental metal. If present in excess, NMMO is degraded in a highly exothermic and uncontrollable autocatalytic process, triggered by the formed $N$-(methylene)morpholinium ions (11), without concomitant metal reduction

reduced. Compared to the above redox systems, the reaction requires relatively high temperatures of $115^{\circ} \mathrm{C}$ and above and is relatively slow with reaction times of $30 \mathrm{~min}$ up to several hours for complete metal ion reduction. Apart from the easily affected reducing ends also cellulosic hydroxyl groups are oxidized. Additionally, the basic medium-mainly because of the generated $N$-methylmorpholine-causes chain degradation according to beta-alkoxy-elimination pathways (Hosoya et al. 2018) starting from the introduced carbonyl groups (Figs. 1, 3 and 5).

If no other co-reactant is present, excess transition metal ions can oxidize intermediate $N$-(methylene)morpholinium ions and $N$-hydroxymethylmorpholine, the product of a metal ion-induced intramolecular rearrangement of NMMO, to $\mathrm{N}$-formylmorpholine (10), with the metal ions being reduced to elemental metal, in turn (Scheme 3). This reaction, proceeding at $120{ }^{\circ} \mathrm{C}$ and above, does not proceed in aqueous NMMO solutions, but requires NMMO or its monohydrate, which can, however, be diluted with inert organic solvents. Caution must be exercised that the NMMO is slowly and carefully added to an excess of metal ions since otherwise the $N$-(methylene)morpholinium species will react with NMMO instead of the metal ions, and trigger the non-controllable autocatalytic degradation of the amine $\mathrm{N}$-oxide.

With the present study on the chemical reaction mechanism of transition metal (nano)particle generation on cellulosics in aqueous NMMO, we hope to 
contribute to a better understanding of the chemical aspects of this interesting system and these intriguing materials and to correct certain inconsistencies in the description of the role of NMMO and the underlying chemistry.

Acknowledgments The authors would like to thank the Austrian Biorefinery Center Tulln (ABCT) for financial support.

Authors' contributions All authors contributed to the study conception and design. Material preparation, data collection and analysis were performed by all authors. The first draft of the manuscript was written by T.R. and H.H. and all authors commented on previous versions of the manuscript. All authors read and approved the final manuscript.

Funding Open access funding provided by University of Natural Resources and Life Sciences Vienna (BOKU). The financial support by the Austrian Biorefinery Center Tulln $(\mathrm{ABCT})$ is gratefully acknowledged.

Availability of data and material Data available from the authors upon request.

\section{Declarations}

Conflict of interest The authors declare that they have no conflict of interest.

Consent for publication All authors agreed to the publication in the submitted form.

Open Access This article is licensed under a Creative Commons Attribution 4.0 International License, which permits use, sharing, adaptation, distribution and reproduction in any medium or format, as long as you give appropriate credit to the original author(s) and the source, provide a link to the Creative Commons licence, and indicate if changes were made. The images or other third party material in this article are included in the article's Creative Commons licence, unless indicated otherwise in a credit line to the material. If material is not included in the article's Creative Commons licence and your intended use is not permitted by statutory regulation or exceeds the permitted use, you will need to obtain permission directly from the copyright holder. To view a copy of this licence, visit http://creativecommons.org/licenses/by/4.0/.

\section{References}

Aguilar-Zárate $\mathrm{P}$, Wong-Paz JE, Buenrostro-Figueroa JJ, Ascacio JA, Contreras-Esquivel JC, Aguilar CN (2018) Ellagitannins: Bioavailability, purification and biotechnological degradation. Mini Rev Med Chem 18(15):1244-1252

Ahn K, Zaccaron S, Rosenau T, Potthast A (2019) How alkaline solvents in viscosity measurements affect data for oxidatively damaged celluloses. Part 1. Cupi-ethylenediamine. Biomacromol 20(11):4117-4125

Albini A (1993) Synthetic utility of amine $N$-oxides. Synthesis 1993(3):263-277

Becker M, Liebner F, Rosenau T, Potthast A (2013) Ethoximation-silylation approach with expanded retention index (ERI) for mono- and disaccharide analysis by GC/MS. Talanta 115:642-651

Bleuler H, Perkin AG (1916) An oxidation product of gallic acid. J Chem Soc Trans 109:529-543

Bohrn R, Potthast A, Schiehser S, Rosenau T, Sixta H, Kosma P (2006) A novel method for the determination of carboxyl profiles in cellulosics by fluorescence labelling. Part I. Method development. Biomacromol 7:1743-1750

Chrapava S, Touraud D, Rosenau T, Potthast A, Kunz W (2003) The investigation of the influence of water and temperature on the LiCl/DMAc/cellulose system. Phys Chem Chem Phys 5:1842-1847

Coleman KS, Bedel LJL, Osborn JA (2000) Catalytic oxidation of alcohols to aldehydes or ketones using osmium-oxo complexes with sulfoxides or $N$-methylmorpholine- $N$-oxide as the co-oxidant: a comparative study. C R Acad Sci Ser IIc: Chem 3(10):765-769

Dasgupta B, Donaldson WA (1998) Chemoselective, metalmediated oxidation of (dienol)iron complexes with $\mathrm{N}$ methylmorpholine $N$-oxide. Tetrahedron Lett 39:343-346

Díaz Hidalgo RJ, Córdoba R, Nabais P, Silva V, Melo MJ, Pina F, Teixeira N, Freitas V (2018) New insights into iron-gall inks through the use of historically accurate reconstructions. Heritage Sci 6(1):63

Erdman A, Kulpinski P, Grzyb T, Lis S (2016) Preparation of multicolor luminescent cellulose fibers containing lanthanide doped inorganic nanomaterials. J Luminesc 169:520-527

Fink HP, Weigel P, Purz HJ, Ganster J (2001) Structure formation of regenerated cellulose materials from NMMOsolutions. Progr Polym Sci 26(9):1473-1524

Firgo H, Eibl M, Eichinger D (1995) Lyocell—an ecological alternative. Lenzinger Ber 75:47-50

Gagnaire D, Vincendon M (1973) Étude par r.m.n. de la stéreochimie et de la réactivité des extrémités réductrices de dérivés de polysaccharides. Carbohydr Res 31(2):367-376

Gomes M Jr, Antunes OAC (2001) Upjohn catalytic osmium tetroxide oxidation process: diastereoselective dihydroxylation of monoterpenes. Cat Comm 2(6-7):225-227

Hatakeyama M, Ryuno D, Yokota S, Ichinose H, Kitaoka T (2019) One-step synthesis of cellooligomer-conjugated gold nanoparticles in a water-in-oil emulsion system and their application in biological sensing. Coll Surf B Biointerfaces 178:74-79

Henniges U, Hasani M, Potthast A, Westman G, Rosenau T (2013) Electron beam irradiation of cellulosic materialsopportunities and limitations. Materials 6(5):1584-1598

Holleman AF, Wiberg E (1985a) Lehrbuch der Anorganischen Chemie, 91-100 ed. Walter de Gruyter, Berlin, New York, pp 422-425

Holleman AF, Wiberg E (1985b) Lehrbuch der Anorganischen Chemie, 91-100 ed. Walter de Gruyter, Berlin, New York, pp 1204-1206

Jourdes M, Pouységu L, Quideau S, Mattivi F, Truchado P, Tomás-Barberán FA (2012) Hydrolyzable tannins: 
Gallotannins, ellagitannins, and ellagic acid. In: Handbook of analysis of active compounds in functional foods, pp 435-459

Kato K (1959) The silver staining method for cross sections of regenerated cellulose fibers. Textile Res J 29(5):409-415

Kitaoka T, Yokota S, Opietnik M, Rosenau T (2011) Synthesis and bio-applications of carbohydrate-gold nanoconjugates with nanoparticle and nanolayer forms. Mat Sci Eng C 31(6):1221-1229

Kuga S, Brown MR Jr (1988) Silver labeling of the reducing ends of bacterial cellulose. Carbohydr Res 180(2):345-350

Kukushkin YN (1991) Isomers of platinum(II) and palladium(II) complexes-predicting the direction of isomerisation and relative thermodynamic stability. Platinum Met Rev 35(1):28-31

Kulpinski P, Namyslak M, Grzyb T, Lis S (2012) Luminescent cellulose fibers activated by $\mathrm{Eu}^{3+}$-doped nanoparticles. Cellulose 19(4):1271-1278

Kulpinski P, Erdman A, Grzyb T, Lis S (2016) Luminescent cellulose fibers modified with cerium fluoride doped with terbium particles. Polym Compos 37(1):153-160

Linton EP (1940) The dipole moment of amine oxides. J Am Chem Soc 62:1945-1948

Marini I, Brauneis F (1996) Lyocell-die wichtigsten Unterschiede zu den anderen cellulosischen Fasern. Textilveredelung 31:182-187

Melo MJ, Nabais P, Araújo R, Vitorino T (2019) The conservation of medieval manuscript illuminations: a chemical perspective. Phys Sci Rev 4(8):20180017

Pieterse T (2013) $N$-Methylmorpholine $N$-oxide. Synlett 24(16):2175-2176

Potthast A, Rosenau T, Kosma P, Chen CL, Gratzl JS (2000) Confirmation of the presence of formaldehyde and $\mathrm{N}$ (Methylene)morpholinium cations as reactive species in the cellulose/NMMO/water system by trapping reactions. Holzforschung 54:101-103

Potthast A, Röhrling J, Rosenau T, Borgards A, Sixta H, Kosma $\mathrm{P}$ (2003) A novel method for the determination of carbonyl groups in cellulosics by fluorescence labelling. 3. Monitoring oxidative processes. Biomacromol 4(3):743-749

Potthast A, Rosenau T, Kosma P, Saariaho AM, Vuorinen T, Sixta $H$ (2005) On the nature of carbonyl groups in cellulosic pulps. Cellulose 12(1):43-50

Potthast A, Rosenau T, Henniges U, Schiehser S, Kosma P, Saake B, Lebioda S, Radosta S, Vorwerg W, Wetzel H, Koschella A, Heinze T, Strobin G, Sixta H, Strlic M, Isogai A (2015) Comparison testing of methods for gel permeation chromatography of cellulose: coming closer to a standard protocol. Cellulose 22(3):1591-1613

Rac-Rumijowska O, Fiedot M, Karbownik I, Suchorska-Woźniak P, Teterycz H (2017) Synthesis of silver nanoparticles in NMMO and their in situ doping into cellulose fibers. Cellulose 24(3):1355-1370

Rac-Rumijowska O, Maliszewska I, Fiedot-Toboła M, Karbownik I, Teterycz H (2019) Multifunctional nanocomposite cellulose fibers doped in situ with silver nanoparticles. Polymers 11(3):562

Röhrling J, Potthast A, Rosenau T, Lange T, Borgards A, Sixta H, Kosma P (2002a) A novel method for the determination of carbonyl groups in cellulosics by fluorescence labelling. 2. Validation and applications. Biomacromol 2(3):969-975
Röhrling J, Potthast A, Rosenau T, Lange T, Ebner G, Sixta H, Kosma P (2002b) A novel method for the determination of carbonyl groups in cellulosics by fluorescence labelling. 1 . Method development. Biomacromol 2(3):959-968

Rosenau T, French AD (2021) $N$-Methylmorpholine- $N$-oxide (NMMO) - hazards in practice and pitfalls in theory. Cellulose 28(10):5985-5990. https://doi.org/10.1007/s10570021-03860-4

Rosenau T, Potthast A, Kosma P, Chen CL, Gratzl JS (1999) Autocatalytic decomposition of $N$-methylmorpholine- $N$ oxide Induced by Mannich intermediates. J Org Chem 64:2166-2167

Rosenau T, Potthast A, Sixta H, Kosma P (2001) The chemistry of side reactions and byproduct formation in the system NMMO/cellulose (Lyocell process). Progr Polym Sci 26(9):1763-1837

Rosenau T, Potthast A, Adorjan I, Hofinger A, Sixta H, Firgo H, Kosma P (2002a) Cellulose solutions in $\mathrm{N}$-methylmorpholine- $N$-oxide (NMMO)-degradation processes and stabilizers. Cellulose 9(3-4):283-291

Rosenau T, Potthast A, Kosma P (2002b) Studies into reactions of $\mathrm{N}$-methyl-morpholine- $\mathrm{N}$-oxide (NMMO) and its hydrates with cyanuric chloride. Tetrahedron 58:9808-9815

Rosenau T, Hofinger A, Potthast A, Kosma P (2004) A general, selective high-yield $N$-demethylation procedure for tertiary amines by solid reagents in a convenient column chromatography-like setup. Org Lett 6(4):541-544

Rosenau T, Potthast A, Milacher W, Adorjan I, Hofinger A, Kosma P (2005a) Discoloration of cellulose solutions in $N$ methyl-morpholine- $N$-oxide (Lyocell). Part 2: isolation and Identification of Chromophores. Cellulose 12(2):197-208

Rosenau T, Schmid P, Potthast A, Kosma P (2005b) Stabilization of cellulose solutions in $N$-methylmorpholine- $N$-oxide (Lyocell dopes) by addition of an $\mathrm{N}$-oxide as sacrificial substrate. Holzforschung 59(5):503-506

Sayyed AJ, Deshmukh NA, Pinjari DV (2019) A critical review of manufacturing processes used in regenerated cellulosic fibres: viscose, cellulose acetate, cuprammonium, LiCl/ DMAc, ionic liquids, and NMMO based Lyocell. Cellulose 26(5):2913-2940

Shah N, Ul-Islam M, Khattak WA, Park JK (2013) Overview of bacterial cellulose composites: a multipurpose advanced material. Carbohydr Polym 98(2):1585-1598

Skwierczyńska M, Runowski M, Kulpiński P, Lis S (2019) Modification of cellulose fibers with inorganic luminescent nanoparticles based on lanthanide(III) ions. Carbohydr Polym 206:742-748

Smiechowicz E, Kulpinski P, Niekraszewicz B, Bacciarelli A (2011) Cellulose fibers modified with silver nanoparticles. Cellulose 18(4):975-985

Smiechowicz E, Niekraszewicz B, Kulpinski P, Dzitko K (2018) Antibacterial composite cellulose fibers modified with silver nanoparticles and nanosilica. Cellulose 25(6):3499-3517

Smiechowicz E, Niekraszewicz B, Strzelinska M, Zielecka M (2020) Antibacterial fibers containing nanosilica with immobilized silver nanoparticles. Autex Res J 20(4):441-448

Yokota S, Kitaoka T, Opietnik M, Rosenau T, Wariishi H (2008) Synthesis of gold nanoparticles for in situ conjugation with structural carbohydrates. Angew Chem Int Ed Engl 47:9866-9869 
Zervos S, Alexopoulou I (2015) Paper conservation methods: a literature review. Cellulose 22(5):2859-2897

Zuckerstätter G, Schild G, Wollboldt RT, Weber HK, Sixta H (2009) The elucidation of cellulose supramolecular structure by ${ }^{13} \mathrm{C}$ CP-MAS NMR. Lenzinger Ber 87:38-46
Publisher's Note Springer Nature remains neutral with regard to jurisdictional claims in published maps and institutional affiliations. 